\title{
De emotionele beleving van kwalitatief onderzoekers bij onderzoek naar kwetsbare groepen en gevoelige thema's
}

\author{
Ciska Wittouck \& Gwen Herkes
}

\section{Inleiding}

Een kwalitatief onderzoeker gaat tijdens het veldwerk een diepgaande en vaak langdurige band aan met de deelnemers, doelgroep of informanten ${ }^{1}$ (Lincoln \& Guba, 1985). Typisch voor kwalitatief onderzoek is de aandacht voor de subjectieve leefwereld van mensen om te begrijpen op welke manier deze mensen hun wereld of een bepaalde gebeurtenis interpreteren en betekenis geven en reageren op deze interpretatie en betekenis (Hammersley, 2013; Mortelmans, 2013). Een gevolg hiervan is dat kwalitatief onderzoekers tijdens het werk geconfronteerd kunnen worden met emoties, vooral wanneer kwetsbare personen of gevoelige onderwerpen onderzocht worden (Butler, Copnell \& Hall, 2019; Gilbert, 2000; Mazzetti, 2018). Naast kenmerken van de onderzoekspopulatie en/of het onderzoeksthema kunnen ook kenmerken van onderzoekers, zoals hun eigen ervaringen of hun sociaal-culturele context, van invloed zijn op hun emotionele beleving van kwalitatief onderzoek (Johnson, 2009; Robben \& Nordstrom, 1995).

In gezondheidsberoepen wordt erkend dat gezondheidswerkers (bijvoorbeeld verpleegsters en therapeuten) tijdens hun werk geconfronteerd kunnen worden met emoties, en dat daarom copingvaardigheden en zorg hierbij noodzakelijk zijn (Riley \& Weiss, 2016).

In de academische wereld blijft positivistisch rationeel denken echter overheersen, zij het dat onder invloed van de feministische onderzoekstraditie meer aandacht is ontstaan voor de emotionele ervaringen van de onderzoeker tijdens het veldwerk. Intussen pogen onderzoekers uit verschillende wetenschappelijke disciplines het gebrek aan aandacht voor emoties in de academische wereld op de agenda te plaatsen, vooral binnen de brede kwalitatieve onderzoekstraditie (Beyens, 2013; Davies, 2010; Gilbert, 2000; Holland, 2007; Kleinman \& Copp, 1993; May \& Perry, 2017; Mazzetti, 2018; McGarrol, 2017; Pollard, 2009; Widdowfield, 1999).

Onderhavige onderzoekers voerden zelf kwalitatief onderzoek uit naar kwetsbare populaties en gevoelige onderwerpen. Gwen Herkes heeft in het kader van haar doctoraatsstudie een kwalitatieve studie uitgevoerd rond slachtofferschap in een context van migratie en mensensmokkel. Hierbij heeft zij 61 asielzoekers en

1 In het vervolg van deze bijdrage wordt naar zowel deelnemers, doelgroepen als informanten verwezen met 'deelnemers'. 
vluchtelingen (uit Afghanistan, Irak, Palestina en Syrië) geïnterviewd en opgevolgd doorheen de tijd. Ook bracht zij gedurende haar empirisch onderzoek tijd door in een opvangcentrum voor asielzoekers, waardoor zij veel in contact stond met deze kwetsbare populatie. Ciska Wittouck heeft voor een onderzoek naar een rouwinterventie iets meer dan 300 huisbezoeken afgelegd bij 83 personen die een naaste hadden verloren door zelfdoding, waarbij de omstandigheden rond de zelfdoding en rouwreacties diepgaand werden besproken. Voor haar doctoraatsonderzoek interviewde zij 116 personen met een psychiatrische problematiek die strafbare feiten hebben gepleegd (en daarvoor ontoerekeningsvatbaar werden verklaard), over hun ervaringen met politie, justitie en (gedwongen) hulpverlening. Tijdens het uitvoeren van deze onderzoeksprojecten werden wij allebei geconfronteerd met emoties en ervaringen zoals machteloosheid en uitputting, en stelden wij ons vragen over de impact van het kwalitatief onderzoek op onderzoekers en hoe hiermee om te gaan als onderzoeker en onderzoeksgroep. $\mathrm{Na}$ enkele informele gesprekken met elkaar over deze emoties, ervaringen en vragen, beslisten wij hier ook op academisch vlak iets mee te doen. Zo organiseerden wij op de conferentie 'Between Edges and Margins'2 een workshop over de emotionele impact van kwalitatief onderzoek naar kwetsbare groepen en gevoelige thema's. Uit het literatuuronderzoek dat wij hebben uitgevoerd tijdens de voorbereiding van deze workshop leerden wij dat reeds veel werd geschreven over dit onderwerp, én dat deze informatie erg fragmentarisch verspreid is in de literatuur.

Deze bijdrage poogt meer coherente kennis te ontwikkelen over de emotionele beleving van kwalitatief onderzoekers. Aan de hand van een niet-exhaustieve narratieve literatuurstudie willen we een antwoord formuleren op de volgende onderzoeksvraag: welke emotionele ervaringen hebben kwalitatieve onderzoekers tijdens het verrichten van onderzoek naar kwetsbare groepen of gevoelige thema's, en welke impact hebben die ervaringen op deze onderzoekers? Als antwoord op deze onderzoeksvraag worden (auto-etnografische) onderzoeksbevindingen over de emotionele beleving van kwalitatief onderzoek op systematische wijze verzameld en gesynthetiseerd. Via deze bijdrage beogen wij meer aandacht en bewustzijn te creëren voor de emotionele aspecten van kwalitatief onderzoek naar kwetsbare groepen en gevoelige onderwerpen, en de academische wereld in zijn geheel, en in het bijzonder docenten, onderzoekers en onderzoeksgroepen aan te moedigen om deze emotionele aspecten op een proactieve wijze te benaderen.

Hierbij dient opgemerkt te worden dat de manier waarop met emoties wordt omgegaan in het kader van onderzoek en het onderwijs daarover niet enkel vanuit het eerste persoonsperspectief van cruciaal belang is (bijvoorbeeld zelfvertrouwen, welbevinden, copingvaardigheden van individuele onderzoekers), maar ook vanuit methodologisch en theoretisch oogpunt (bijvoorbeeld kwaliteit van data, emoties als data) (O'Connor, 2011; Velardo \& Elliot, 2018). In deze bijdrage ligt de focus evenwel op het eerste persoonsperspectief. 


\section{Methode}

In deze bijdrage werd op systematische wijze een literatuurstudie uitgevoerd waarbij de onderzoeksstrategie en de uiteindelijke inclusiecriteria werden bepaald aan de hand van de SPIDER-tool, een instrument voor het systematiseren van literatuurzoektochten naar kwalitatieve en mixed-method studies. Het acronym SPIDER staat voor Sample, Phenomenon of Interest, Design, Evaluation en Research type (Cooke, Smith \& Booth, 2012). Voor de huidige literatuurzoektocht werden deze aspecten als volgt ingevuld:

- populatie: onderzoek naar kwetsbare groepen of over gevoelige onderwerpen;

- onderwerp studie: emotionele impact op onderzoekers;

- design: enkel empirische Engelstalige artikelen waarin gereflecteerd wordt over de eigen onderzoekservaringen via auto-etnografische weergaven of via kwalitatief belevingsonderzoek (eerste persoonsperspectief);

- evaluatie: ervaringen van emoties en gevoelens, context en aanbevelingen;

- type onderzoek: enkel kwalitatief onderzoek.

Er werd een systematische zoektocht uitgevoerd in zowel PubMed als Web of Science. De volgende boleaanse combinatie van zoektermen werd gebruikt (tot december 2018): TI = (emotion* OR ethic* OR reflexiv* OR sensitiv* OR distress* OR stress* OR well-being OR wellbeing OR vulnerab* OR autoethnograp* OR auto-ethnograph* OR feel* OR challeng* OR psychol*) AND TI $=($ research* OR field*) AND ALL = (qualitative OR ethnograph*). Bij de zoektocht in PubMed - die als eerste werd uitgevoerd - werd gebruikgemaakt van nog enkele extra zoektermen, namelijk psychol*, affect*, impact, observ* en interview*. Deze zoektermen werden echter weggelaten bij de zoektocht in Web of Science, aangezien te veel onnuttige hits gegenereerd werden (totaal van 17.784), wat de realiseerbaarheid van het onderzoek in de weg stond. Er werd voor geopteerd de uitgebreide resultaten van de PubMed-zoektocht wel te behouden, aangezien het screeningswerk al vergevorderd was op dat moment.

De zoekstrategie genereerde in totaal meer dan 8.000 hits. Na het screenen op titel en abstract en het uitfilteren van dubbele artikelen, bleven 318 artikelen over. $\mathrm{Na}$ het toepassen van de inclusiecriteria op titel en abstract bleven vervolgens nog 120 artikelen over. Omwille van het grote aantal artikelen dat reeds werd gegenereerd via de zoekopdrachten op Web of Science en PubMed werd om pragmatische redenen besloten om de zoekopdracht niet uit te breiden met het screenen van referentielijsten, (hand)boeken en grijze literatuur.

Door de omvang van het aantal geïncludeerde artikelen, werden 60 artikelen toebedeeld aan elk van beide auteurs. De volledige tekst van deze bijdragen werd gescreend op basis van de inclusiecriteria, waarna uiteindelijk 82 bijdragen werden betrokken in deze literatuurstudie (zie tabel 1 en de met een * gemarkeerde literatuur in de literatuurlijst). De analyse van de artikelen is gebaseerd op thematische analyse (Clarke \& Braun, 2006). Alle eerste persoonsbeschrijvingen in de geïncludeerde artikelen werden inductief en zin voor zin gecodeerd op basis van de gerapporteerde emoties en gevoelens, context en aanbevelingen. Tijdens verschillende overlegmomenten werden deze verschillende codes en hun samenhang 
besproken en werden deze inhoudelijk georganiseerd in voorlopige thema's. Via verdere analyse en bespreking van deze codes en thema's werden de uiteindelijke thema's geïdentificeerd die hieronder worden weergegeven.

\section{Bevindingen}

\section{Context van de geïncludeerde artikelen}

Alvorens over te gaan tot de bespreking van de bevindingen van deze systematische literatuurstudie, wordt kort ingegaan op de context van de 82 geïncludeerde artikelen (zie tabel 1). Deze artikelen zijn afkomstig uit een brede waaier van wetenschappelijke disciplines, ${ }^{3}$ namelijk gezondheidswetenschappen (33), sociologie (10), psychologie en sociaal werk (8), criminologie (8), antropologie (6), pedagogie (5), geografie (5), economie en bedrijfswetenschappen (3), conflict- en ontwikkelingsstudies (2), communicatiewetenschappen (1) en rechten (1). Naast de disciplines waaruit deze bijdragen afkomstig zijn, werd ook in kaart gebracht wat de bredere onderzoeksthema's van deze bijdragen betroffen. Deze thema's werden over de verschillende disciplines heen beschreven. ${ }^{4}$ De brede onderzoeksthema's die voornamelijk werden teruggevonden in de geïncludeerde artikelen zijn ziektes of (psychiatrische) aandoeningen (18), onderzoekers (12), ${ }^{5}$ criminaliteit en deviantie (8), gemeenschappen (6), migratie (6), gender (6), kinderen of jongeren (6), werk(omstandigheden) (5), conflict (5), detentie (5), ouders (5), seksuele onderwerpen (5), overlijden (3), huisvesting (3), ouderen (2), en personen met een beperking (2).

Opvallend hierbij is dat de grote meerderheid van de geïncludeerde bijdragen werd geschreven door auteurs uit de gezondheidswetenschappen, waarin dikwijls gerapporteerd wordt over ervaringen van onderzoekers bij het onderzoeken van bepaalde ziektes of aandoeningen zoals kanker, hartfalen, ernstige mentale aandoeningen, suïcide en depressie. Binnen de criminologische discipline werden (slechts) acht bijdragen teruggevonden. Opvallend daarbij is dat de helft van deze bijdragen focust op ervaringen van onderzoekers in een detentiecontext.

Verder blijkt ook dat de auto-etnografische bespreking van emoties en gevoelens een hoofdzakelijk vrouwelijke aangelegenheid is. Slechts 9 van de 82 geïncludeerde artikelen werden enkel door mannelijke auteurs geschreven en tien artikelen werden geschreven door een team van vrouwen en mannen als eerste en tweede auteurs. Alle andere bijdragen (63) werden geschreven door (een team van) vrouwelijke onderzoekers.

3 De onderzoekers hebben een eigen clustering gehanteerd aangezien sommige aangegeven disciplines door de auteurs van de geïncludeerde bijdragen erg gedetailleerd waren.

4 Sommige bijdragen hebben betrekking op meerdere brede onderzoeksthema's.

5 Het brede onderzoeksthema 'onderzoekers' betreft deze bijdragen die zelf rapporteren over empirisch werk bij verschillende onderzoekers binnen de eigen discipline. 
Tabel 1 Context geïncludeerde bijdragen

\begin{tabular}{|c|c|c|c|c|}
\hline Auteur \& jaar & $\begin{array}{l}\text { Gender } \\
\text { auteurs }\end{array}$ & $\begin{array}{l}\text { Wetenschappe- } \\
\text { lijke discipline }\end{array}$ & $\begin{array}{l}\text { Bredere } \\
\text { thema's }\end{array}$ & $\begin{array}{l}\text { Onderwerp onder- } \\
\text { zoek }\end{array}$ \\
\hline Adams, E. (20I0) & Vrouw & $\begin{array}{l}\text { Gezondheidswe- } \\
\text { tenschappen }\end{array}$ & Onderzoekers & $\begin{array}{l}\text { Onderzoekers } \\
\text { gezondheidsweten- } \\
\text { schappen }\end{array}$ \\
\hline $\begin{array}{l}\text { Adikaram, A.S. } \\
(20 \mid 8)\end{array}$ & Vrouw & $\begin{array}{l}\text { Economische } \\
\text { wetenschappen - } \\
\text { HR }\end{array}$ & $\begin{array}{l}\text { Seksuele onder- } \\
\text { werpen }\end{array}$ & $\begin{array}{l}\text { Grensoverschrijdend } \\
\text { gedrag }\end{array}$ \\
\hline $\begin{array}{l}\text { Anwar, N.H. \& } \\
\text { Viqar, S. (20I7) }\end{array}$ & Vrouw & Antropologie & Onderzoekers & $\begin{array}{l}\text { Onderzoekers } \\
\text { antropologie }\end{array}$ \\
\hline $\begin{array}{l}\text { Bahn, S. \& Wea- } \\
\text { therill, P. (2013) }\end{array}$ & Vrouw & $\begin{array}{l}\text { Gezondheidswe- } \\
\text { tenschappen }\end{array}$ & Onderzoekers & $\begin{array}{l}\text { Onderzoekers } \\
\text { gezondheidsweten- } \\
\text { schappen }\end{array}$ \\
\hline Bashir, N. (2018) & Vrouw & $\begin{array}{l}\text { Economische } \\
\text { wetenschappen }\end{array}$ & Wonen & Huisvesting \\
\hline $\begin{array}{l}\text { Beale, B. et al. } \\
(2004)\end{array}$ & Vrouw & $\begin{array}{l}\text { Gezondheidswe- } \\
\text { tenschappen }\end{array}$ & $\begin{array}{l}\text { Ziektes of aan- } \\
\text { doeningen }\end{array}$ & Eetstoornissen \\
\hline $\begin{array}{l}\text { Benoot, C. \& Bil- } \\
\text { sen, J. (2016) }\end{array}$ & Vrouw & $\begin{array}{l}\text { Gezondheidswe- } \\
\text { tenschappen }\end{array}$ & $\begin{array}{l}\text { Ziektes of aan- } \\
\text { doeningen }\end{array}$ & Kanker \\
\hline $\begin{array}{l}\text { Blaisdell, C. } \\
(20 \mid 5)\end{array}$ & Vrouw & $\begin{array}{l}\text { Pedagogische } \\
\text { wetenschappen }\end{array}$ & $\begin{array}{l}\text { Kinderen of jon- } \\
\text { geren }\end{array}$ & Leren en kinderopvang \\
\hline $\begin{array}{l}\text { Boden, Z. V.R. et } \\
\text { al. }(2016)\end{array}$ & Vrouw & $\begin{array}{l}\text { Gezondheidswe- } \\
\text { tenschappen }\end{array}$ & $\begin{array}{l}\text { Ziektes of aan- } \\
\text { doeningen }\end{array}$ & Suïcide \\
\hline Bott, E. (2010) & Vrouw & Sociologie & Migratie & Migratie \\
\hline $\begin{array}{l}\text { Brandt, F. \& } \\
\text { Josefsson, J. } \\
(20 \mid 7)\end{array}$ & Vrouw & Antropologie & $\begin{array}{l}\text { Seksuele onder- } \\
\text { werpen }\end{array}$ & Seksualiteit \\
\hline $\begin{array}{l}\text { Browne, B.C. } \\
(2013)\end{array}$ & Man & Rechten & Conflict & Conflictgebieden \\
\hline $\begin{array}{l}\text { Caretta, M.A. \& } \\
\text { Jokinen, J.C. } \\
(20 \mid 7)\end{array}$ & Vrouw & Geografie & $\begin{array}{l}\text { Migratie \& Con- } \\
\text { flict }\end{array}$ & Migratie \\
\hline Carroll, K. (20I3) & Vrouw & $\begin{array}{l}\text { Gezondheidswe- } \\
\text { tenschappen }\end{array}$ & $\begin{array}{l}\text { Ziektes of aan- } \\
\text { doeningen }\end{array}$ & In vitro fertilisatie \\
\hline $\begin{array}{l}\text { Cartwright, J. \& } \\
\text { Limandri, B. } \\
\text { (1997) }\end{array}$ & Vrouw & $\begin{array}{l}\text { Gezondheidswe- } \\
\text { tenschappen }\end{array}$ & Ouderen & Ouderenzorg \\
\hline Case, A.D. (2017) & Man & $\begin{array}{l}\text { Psychologie en } \\
\text { sociaal werk }\end{array}$ & $\begin{array}{l}\text { Detentie \& Kin- } \\
\text { deren of jongeren }\end{array}$ & Detentie van jongeren \\
\hline $\begin{array}{l}\text { Chong, K.H. } \\
(2008)\end{array}$ & Vrouw & Sociologie & Gemeenschappen & $\begin{array}{l}\text { Conservatieve Zuid- } \\
\text { Koreaanse gemeen- } \\
\text { schap }\end{array}$ \\
\hline Clancy, A. (20II) & Vrouw & $\begin{array}{l}\text { Gezondheidswe- } \\
\text { tenschappen }\end{array}$ & Onderzoekers & $\begin{array}{l}\text { Onderzoekers verple- } \\
\text { gers }\end{array}$ \\
\hline $\begin{array}{l}\text { Damsa, D. \& } \\
\text { Ugelvik, T. (20I7) }\end{array}$ & $\begin{array}{l}\text { Vrouw en } \\
\text { Man }\end{array}$ & Criminologie & Detentie & Detentie \\
\hline
\end{tabular}


Tabel 1 (Vervolg)

\begin{tabular}{|c|c|c|c|c|}
\hline Auteur \& jaar & $\begin{array}{l}\text { Gender } \\
\text { auteurs }\end{array}$ & $\begin{array}{l}\text { Wetenschappe- } \\
\text { lijke discipline }\end{array}$ & $\begin{array}{l}\text { Bredere } \\
\text { thema's }\end{array}$ & $\begin{array}{l}\text { Onderwerp onder- } \\
\text { zoek }\end{array}$ \\
\hline Davison, J. (2004) & Vrouw & $\begin{array}{l}\text { Psychologie en } \\
\text { sociaal werk }\end{array}$ & Onderzoekers & $\begin{array}{l}\text { Onderzoekers sociaal } \\
\text { werk }\end{array}$ \\
\hline $\begin{array}{l}\text { deMarrais, K. \& } \\
\text { Tisdale, K. (2002) }\end{array}$ & Vrouw & $\begin{array}{l}\text { Psychologie en } \\
\text { sociaal werk }\end{array}$ & $\begin{array}{l}\text { Werkomstandig- } \\
\text { heden }\end{array}$ & $\begin{array}{l}\text { Boosheid bij leer- } \\
\text { krachten }\end{array}$ \\
\hline $\begin{array}{l}\text { Dickson-Swift, V. } \\
\text { et al. (2006) }\end{array}$ & Vrouw & $\begin{array}{l}\text { Gezondheidswe- } \\
\text { tenschappen }\end{array}$ & Onderzoekers & $\begin{array}{l}\text { Onderzoekers } \\
\text { gezondheidsweten- } \\
\text { schappen }\end{array}$ \\
\hline $\begin{array}{l}\text { Dickson-Swift, V. } \\
\text { et al. (2009) }\end{array}$ & Vrouw & $\begin{array}{l}\text { Gezondheidswe- } \\
\text { tenschappen }\end{array}$ & Onderzoekers & $\begin{array}{l}\text { Onderzoekers } \\
\text { gezondheidsweten- } \\
\text { schappen }\end{array}$ \\
\hline $\begin{array}{l}\text { Diphoorn, T. } \\
(20 \mid 3)\end{array}$ & Vrouw & Antropologie & $\begin{array}{l}\text { Criminaliteit en } \\
\text { deviantie }\end{array}$ & Private politie \\
\hline $\begin{array}{l}\text { Drake, D.H. \& } \\
\text { Harvey, J. (2014) }\end{array}$ & $\begin{array}{l}\text { Vrouw en } \\
\text { Man }\end{array}$ & Criminologie & Detentie & Detentie \\
\hline $\begin{array}{l}\text { Dupuis, S.L. } \\
\text { (1999) }\end{array}$ & Vrouw & $\begin{array}{l}\text { Sociologie - vrije- } \\
\text { tijd studies }\end{array}$ & Onderzoekers & $\begin{array}{l}\text { Onderzoekers vrije- } \\
\text { tijdsstudies }\end{array}$ \\
\hline $\begin{array}{l}\text { Emerald, E. \& } \\
\text { Carpenter, L. } \\
(2015)\end{array}$ & Vrouw & $\begin{array}{l}\text { Pedagogische } \\
\text { wetenschappen }\end{array}$ & $\begin{array}{l}\text { Handicap \& } \\
\text { Ouders }\end{array}$ & $\begin{array}{l}\text { Moeders met gehandi- } \\
\text { capte kinderen }\end{array}$ \\
\hline $\begin{array}{l}\text { Evans, R. et al. } \\
(2017)\end{array}$ & Vrouw & Geografie & Overlijden & $\begin{array}{l}\text { Impact overlijden van } \\
\text { familielid }\end{array}$ \\
\hline Fahie, D. (2014) & Man & $\begin{array}{l}\text { Pedagogische } \\
\text { wetenschappen }\end{array}$ & $\begin{array}{l}\text { Werkomstandig- } \\
\text { heden }\end{array}$ & Pesten op het werk \\
\hline $\begin{array}{l}\text { Gabriel, L. et al. } \\
(20 \mid 7)\end{array}$ & Vrouw & $\begin{array}{l}\text { Psychologie en } \\
\text { sociaal werk }\end{array}$ & $\begin{array}{l}\text { Criminaliteit en } \\
\text { deviantie }\end{array}$ & Intrafamiliaal geweld \\
\hline Harris, M. (2015) & Vrouw & $\begin{array}{l}\text { Gezondheidswe- } \\
\text { tenschappen }\end{array}$ & $\begin{array}{l}\text { Criminaliteit en } \\
\text { deviantie \& Ziek- } \\
\text { tes of aandoenin- } \\
\text { gen }\end{array}$ & $\begin{array}{l}\text { Hepatitis C en drugge- } \\
\text { bruik }\end{array}$ \\
\hline Horton, J. (2008) & Man & Geografie & $\begin{array}{l}\text { Kinderen of jon- } \\
\text { geren }\end{array}$ & Kinderen \\
\hline $\begin{array}{l}\text { Huijsmans, R. } \\
(20 \mid 8)\end{array}$ & Man & Geografie & $\begin{array}{l}\text { Migratie \& Kinde- } \\
\text { ren of jongeren }\end{array}$ & Migratie - kinderen \\
\hline $\begin{array}{l}\text { Huisman, K. } \\
(2008)\end{array}$ & Vrouw & Sociologie & Migratie & $\begin{array}{l}\text { Migratie - vluchtelin- } \\
\text { gen }\end{array}$ \\
\hline $\begin{array}{l}\text { Ibarra, P.R. \& } \\
\text { Kusenbach, M. } \\
(2001)\end{array}$ & $\begin{array}{l}\text { Man en } \\
\text { Vrouw }\end{array}$ & Sociologie & Wonen & $\begin{array}{l}\text { Wonen - buurten en } \\
\text { buren }\end{array}$ \\
\hline Jewkes, Y. (20I2) & Vrouw & Criminologie & Detentie & Detentie \\
\hline $\begin{array}{l}\text { Johnson, B. \& } \\
\text { Clarke, J.M. } \\
(2003)\end{array}$ & Vrouw & $\begin{array}{l}\text { Gezondheidswe- } \\
\text { tenschappen }\end{array}$ & $\begin{array}{l}\text { Ziektes of aan- } \\
\text { doeningen }\end{array}$ & $\begin{array}{l}\text { Kanker, HIV, overlij- } \\
\text { den }\end{array}$ \\
\hline $\begin{array}{l}\text { Kay, R. \& Old- } \\
\text { field, J. (20I I) }\end{array}$ & $\begin{array}{l}\text { Vrouw en } \\
\text { Man }\end{array}$ & Geografie & Gender & $\begin{array}{l}\text { Vrouwenorganisaties } \\
\text { in Rusland }\end{array}$ \\
\hline
\end{tabular}


Tabel 1 (Vervolg)

\begin{tabular}{|c|c|c|c|c|}
\hline Auteur \& jaar & $\begin{array}{l}\text { Gender } \\
\text { auteurs }\end{array}$ & $\begin{array}{l}\text { Wetenschappe- } \\
\text { lijke discipline }\end{array}$ & $\begin{array}{l}\text { Bredere } \\
\text { thema's }\end{array}$ & $\begin{array}{l}\text { Onderwerp onder- } \\
\text { zoek }\end{array}$ \\
\hline $\begin{array}{l}\text { Kendall, M. et al. } \\
(2007)\end{array}$ & Vrouw & $\begin{array}{l}\text { Gezondheidswe- } \\
\text { tenschappen }\end{array}$ & $\begin{array}{l}\text { Ziektes of aan- } \\
\text { doeningen }\end{array}$ & Kanker \\
\hline $\begin{array}{l}\text { Kennedy, F. et al. } \\
(2014)\end{array}$ & $\begin{array}{l}\text { Vrouw en } \\
\text { Man }\end{array}$ & $\begin{array}{l}\text { Gezondheidswe- } \\
\text { tenschappen }\end{array}$ & $\begin{array}{l}\text { Ziektes of aan- } \\
\text { doeningen }\end{array}$ & Kanker \\
\hline $\begin{array}{l}\text { Klein, J.L. et al. } \\
(2018)\end{array}$ & Vrouw & Criminologie & $\begin{array}{l}\text { Seksuele onder- } \\
\text { werpen }\end{array}$ & Seksuele misdrijven \\
\hline $\begin{array}{l}\text { Kumar, S. \& } \\
\text { Cavallaro, L. } \\
(2018)\end{array}$ & Vrouw & $\begin{array}{l}\text { Gezondheidswe- } \\
\text { tenschappen }\end{array}$ & $\begin{array}{l}\text { Criminaliteit en } \\
\text { deviantie \& } \\
\text { Werkomstandig- } \\
\text { heden }\end{array}$ & $\begin{array}{l}\text { Intrafamiliaal geweld, } \\
\text { compassion fatigue }\end{array}$ \\
\hline $\begin{array}{l}\text { Lalor, J.G. et al. } \\
(2006)\end{array}$ & Vrouw & $\begin{array}{l}\text { Gezondheidswe- } \\
\text { tenschappen }\end{array}$ & Overlijden & Rouwen \\
\hline Levy, N. (2016) & Vrouw & Sociologie & Gemeenschappen & $\begin{array}{l}\text { Radicale ecogemeen- } \\
\text { schappen in de VS }\end{array}$ \\
\hline $\begin{array}{l}\text { Lumsden, K. } \\
(2013)\end{array}$ & Vrouw & Sociologie & $\begin{array}{l}\text { Criminaliteit en } \\
\text { deviantie \& Kin- } \\
\text { deren of jongeren }\end{array}$ & Jonge racers \\
\hline $\begin{array}{l}\text { Madziva, R. } \\
(20 \mid 5)\end{array}$ & Vrouw & Sociologie & $\begin{array}{l}\text { Migratie \& } \\
\text { Ouders }\end{array}$ & $\begin{array}{l}\text { Migratie - ouders uit } \\
\text { Zimbabwe }\end{array}$ \\
\hline $\begin{array}{l}\text { Malacrida, C. } \\
(2007)\end{array}$ & Vrouw & $\begin{array}{l}\text { Gezondheidswe- } \\
\text { tenschappen }\end{array}$ & $\begin{array}{l}\text { Handicap \& } \\
\text { Ouders }\end{array}$ & $\begin{array}{l}\text { Gehandicapte moe- } \\
\text { ders }\end{array}$ \\
\hline $\begin{array}{l}\text { McGarrol, S. } \\
(2017)\end{array}$ & Vrouw & $\begin{array}{l}\text { Gezondheidswe- } \\
\text { tenschappen }\end{array}$ & $\begin{array}{l}\text { Ziektes of aan- } \\
\text { doeningen }\end{array}$ & Hartaanval \\
\hline $\begin{array}{l}\text { McKenzie, J.S. } \\
(2017)\end{array}$ & Man & Sociologie & Wonen & $\begin{array}{l}\text { Wonen - sociale huis- } \\
\text { vesting }\end{array}$ \\
\hline $\begin{array}{l}\text { McQueeney, K. et } \\
\text { al. (20I7) }\end{array}$ & Vrouw & Criminologie & $\begin{array}{l}\text { Gender \& Con- } \\
\text { flict }\end{array}$ & $\begin{array}{l}\text { LGBT in de kerk; men- } \\
\text { senrechten }\end{array}$ \\
\hline $\begin{array}{l}\text { Moreno-Fergus- } \\
\text { son, M.E. et al. } \\
(2016)\end{array}$ & Vrouw & $\begin{array}{l}\text { Gezondheidswe- } \\
\text { tenschappen }\end{array}$ & $\begin{array}{l}\text { Ziektes of aan- } \\
\text { doeningen }\end{array}$ & $\begin{array}{l}\text { Traumatische ervarin- } \\
\text { gen }\end{array}$ \\
\hline $\begin{array}{l}\text { Mosavel, M. et al. } \\
(20 \mathrm{II})\end{array}$ & $\begin{array}{l}\text { Vrouw en } \\
\text { Man }\end{array}$ & $\begin{array}{l}\text { Gezondheidswe- } \\
\text { tenschappen }\end{array}$ & Gemeenschappen & $\begin{array}{l}\text { Verschillen in gezond- } \\
\text { heid }\end{array}$ \\
\hline Moyle, W. (2002) & Vrouw & $\begin{array}{l}\text { Gezondheidswe- } \\
\text { tenschappen }\end{array}$ & $\begin{array}{l}\text { Ziektes of aan- } \\
\text { doeningen }\end{array}$ & Zware depressie \\
\hline $\begin{array}{l}\text { Newman, D. et al. } \\
(20 \mid 7)\end{array}$ & $\begin{array}{l}\text { Man en } \\
\text { Vrouw }\end{array}$ & $\begin{array}{l}\text { Gezondheidswe- } \\
\text { tenschappen }\end{array}$ & $\begin{array}{l}\text { Ziektes of aan- } \\
\text { doeningen }\end{array}$ & $\begin{array}{l}\text { Ernstige mentale aan- } \\
\text { doeningen }\end{array}$ \\
\hline $\begin{array}{l}\text { Nielsen, M.M. } \\
(2010)\end{array}$ & Vrouw & Criminologie & Detentie & Detentie \\
\hline Nilson, C. (2017) & Vrouw & Antropologie & Gemeenschappen & $\begin{array}{l}\text { Aboriginal gemeen- } \\
\text { schap }\end{array}$ \\
\hline $\begin{array}{l}\text { Norander, S. } \\
(2017)\end{array}$ & Vrouw & $\begin{array}{l}\text { Communicatie- } \\
\text { wetenschappen }\end{array}$ & $\begin{array}{l}\text { Gender \& Con- } \\
\text { flict }\end{array}$ & $\begin{array}{l}\text { Vrouwenorganisaties } \\
\text { in post-conflictgebied }\end{array}$ \\
\hline $\begin{array}{l}\text { Ochieng, B.M.N. } \\
(2010)\end{array}$ & Vrouw & $\begin{array}{l}\text { Gezondheidswe- } \\
\text { tenschappen }\end{array}$ & Gemeenschappen & Afrikaanse families \\
\hline
\end{tabular}


Tabel 1 (Vervolg)

\begin{tabular}{|c|c|c|c|c|}
\hline Auteur \& jaar & $\begin{array}{l}\text { Gender } \\
\text { auteurs }\end{array}$ & $\begin{array}{l}\text { Wetenschappe- } \\
\text { lijke discipline }\end{array}$ & $\begin{array}{l}\text { Bredere } \\
\text { thema's }\end{array}$ & $\begin{array}{l}\text { Onderwerp onder- } \\
\text { zoek }\end{array}$ \\
\hline Orsini, A. (2013) & Man & $\begin{array}{l}\text { Conflict- en ont- } \\
\text { wikkelingsstudies }\end{array}$ & $\begin{array}{l}\text { Criminaliteit en } \\
\text { deviantie \& Con- } \\
\text { flict }\end{array}$ & Terrorisme \\
\hline Pellatt, G. (2003) & Vrouw & $\begin{array}{l}\text { Gezondheidswe- } \\
\text { tenschappen }\end{array}$ & $\begin{array}{l}\text { Werkomstandig- } \\
\text { heden }\end{array}$ & $\begin{array}{l}\text { Deelname patiënten } \\
\text { tijdens rehabilitatie }\end{array}$ \\
\hline $\begin{array}{l}\text { Pesonen, H.M. et } \\
\text { al. }(20 \mathrm{II})\end{array}$ & Vrouw & $\begin{array}{l}\text { Gezondheidswe- } \\
\text { tenschappen }\end{array}$ & $\begin{array}{l}\text { Ziektes of aan- } \\
\text { doeningen }\end{array}$ & Vroegdementie \\
\hline Petty, J. (2017) & Vrouw & $\begin{array}{l}\text { Gezondheidswe- } \\
\text { tenschappen }\end{array}$ & Ouders & $\begin{array}{l}\text { Ouders over neona- } \\
\text { tale zorg }\end{array}$ \\
\hline $\begin{array}{l}\text { Pithouse-Morgan, } \\
\text { K. et al. (2012) }\end{array}$ & Vrouw & $\begin{array}{l}\text { Pedagogische } \\
\text { wetenschappen }\end{array}$ & $\begin{array}{l}\text { Ziektes of aan- } \\
\text { doeningen }\end{array}$ & $\begin{array}{l}\text { HIV \& AIDS onder- } \\
\text { zoek bij leerkrachten } \\
\text { en schoolkinderen }\end{array}$ \\
\hline $\begin{array}{l}\text { Rager, K.B. } \\
(2005)\end{array}$ & Vrouw & $\begin{array}{l}\text { Gezondheidswe- } \\
\text { tenschappen }\end{array}$ & $\begin{array}{l}\text { Ziektes of aan- } \\
\text { doeningen }\end{array}$ & Kanker - borstkanker \\
\hline $\begin{array}{l}\text { Raheim, M. et al. } \\
(2016)\end{array}$ & Vrouw & $\begin{array}{l}\text { Gezondheidswe- } \\
\text { tenschappen }\end{array}$ & Onderzoekers & $\begin{array}{l}\text { Onderzoekers } \\
\text { gezondheidsweten- } \\
\text { schappen }\end{array}$ \\
\hline $\begin{array}{l}\text { Redman-MacLa- } \\
\text { ren, M. (20I5) }\end{array}$ & Vrouw & $\begin{array}{l}\text { Gezondheidswe- } \\
\text { tenschappen }\end{array}$ & Gender & $\begin{array}{l}\text { Vrouwen in Papua } \\
\text { New Guinea }\end{array}$ \\
\hline $\begin{array}{l}\text { Rodriguez, L. } \\
(2018)\end{array}$ & Vrouw & $\begin{array}{l}\text { Pedagogische } \\
\text { wetenschappen }\end{array}$ & $\begin{array}{l}\text { Ziektes of aan- } \\
\text { doeningen \& } \\
\text { Ouders }\end{array}$ & Moeders met kanker \\
\hline $\begin{array}{l}\text { Rodriguez- } \\
\text { Dorans, E. (2018) }\end{array}$ & Man & $\begin{array}{l}\text { Psychologie en } \\
\text { sociaal werk }\end{array}$ & $\begin{array}{l}\text { Seksuele onder- } \\
\text { werpen }\end{array}$ & Seksuele topics \\
\hline $\begin{array}{l}\text { Romocea, O. } \\
(20 \mid 4)\end{array}$ & Vrouw & Antropologie & Migratie & Migratie \\
\hline Ross, L.E. (2017) & Vrouw & $\begin{array}{l}\text { Psychologie en } \\
\text { sociaal werk }\end{array}$ & $\begin{array}{l}\text { Ziektes of aan- } \\
\text { doeningen \& Gen- } \\
\text { der }\end{array}$ & $\begin{array}{l}\text { Mentale gezondheid bij } \\
\text { seksuele minderheden }\end{array}$ \\
\hline $\begin{array}{l}\text { Sampson, H. et al. } \\
(2008)\end{array}$ & $\begin{array}{l}\text { Vrouw en } \\
\text { Man }\end{array}$ & Sociologie & Onderzoekers & $\begin{array}{l}\text { Onderzoekers } \\
\text { sociologie }\end{array}$ \\
\hline $\begin{array}{l}\text { Sandberg, S. \& } \\
\text { Copes, H. (20I3) }\end{array}$ & Man & Criminologie & $\begin{array}{l}\text { Criminaliteit en } \\
\text { deviantie }\end{array}$ & Drugsdealers \\
\hline $\begin{array}{l}\text { Scerri, C.S. et al. } \\
(2012)\end{array}$ & Vrouw & $\begin{array}{l}\text { Psychologie en } \\
\text { sociaal werk }\end{array}$ & $\begin{array}{l}\text { Criminaliteit en } \\
\text { deviantie }\end{array}$ & Intrafamiliaal geweld \\
\hline Sinha, S. (2017) & Vrouw & $\begin{array}{l}\text { Gezondheidswe- } \\
\text { tenschappen }\end{array}$ & $\begin{array}{l}\text { Seksuele onder- } \\
\text { werpen \& Werk- } \\
\text { omstandigheden }\end{array}$ & Sekswerk \\
\hline $\begin{array}{l}\text { Sornes, J.O. et al. } \\
(2015)\end{array}$ & $\begin{array}{l}\text { Man en } \\
\text { Vrouw }\end{array}$ & $\begin{array}{l}\text { Economische } \\
\text { wetenschappen - } \\
\text { bedrijfskunde }\end{array}$ & Gender & $\begin{array}{l}\text { Mannelijke managers } \\
\text { en technologie }\end{array}$ \\
\hline Stahlke, S. (20I8) & Vrouw & $\begin{array}{l}\text { Gezondheidswe- } \\
\text { tenschappen }\end{array}$ & Onderzoekers & $\begin{array}{l}\text { Onderzoekers verple- } \\
\text { gers }\end{array}$ \\
\hline $\begin{array}{l}\text { van Dijk, D. } \\
(20 \mid 5)\end{array}$ & Vrouw & $\begin{array}{l}\text { Conflict- en ont- } \\
\text { wikkelingsstudies }\end{array}$ & $\begin{array}{l}\text { Kinderen of jon- } \\
\text { geren }\end{array}$ & $\begin{array}{l}\text { Kinderen als hoofd van } \\
\text { het gezin }\end{array}$ \\
\hline
\end{tabular}


Tabel 1 (Vervolg)

\begin{tabular}{|c|c|c|c|c|}
\hline Auteur \& jaar & $\begin{array}{l}\text { Gender } \\
\text { auteurs }\end{array}$ & $\begin{array}{l}\text { Wetenschappe- } \\
\text { lijke discipline }\end{array}$ & $\begin{array}{l}\text { Bredere } \\
\text { thema's }\end{array}$ & $\begin{array}{l}\text { Onderwerp onder- } \\
\text { zoek }\end{array}$ \\
\hline $\begin{array}{l}\text { Wesser, G. } \\
(2018)\end{array}$ & Vrouw & Antropologie & Gemeenschappen & Rituelen \\
\hline $\begin{array}{l}\text { Wilinska, M. } \\
(20 \mid 4)\end{array}$ & Vrouw & $\begin{array}{l}\text { Psychologie en } \\
\text { sociaal werk }\end{array}$ & Ouderen & Ouderdom in Japan \\
\hline $\begin{array}{l}\text { Woodby, L.L. et } \\
\text { al. (20II) }\end{array}$ & Vrouw & $\begin{array}{l}\text { Gezondheidswe- } \\
\text { tenschappen }\end{array}$ & Overlijden & Overlijden familielid \\
\hline $\begin{array}{l}\text { Worley, R.M. et } \\
\text { al. (20I6) }\end{array}$ & $\begin{array}{l}\text { Man en } \\
\text { Vrouw }\end{array}$ & Criminologie & Onderzoekers & $\begin{array}{l}\text { Onderzoekers } \\
\text { criminologie }\end{array}$ \\
\hline $\begin{array}{l}\text { Wray, N. et al. } \\
(2007)\end{array}$ & Vrouw & $\begin{array}{l}\text { Gezondheidswe- } \\
\text { tenschappen }\end{array}$ & $\begin{array}{l}\text { Ziektes of aan- } \\
\text { doeningen }\end{array}$ & Kanker - gynaecologie \\
\hline
\end{tabular}

De emotionele beleving van kwalitatief onderzoekers

Drie thema's werden geïdentificeerd in de eerste persoonsbeschrijvingen over de emotionele impact van kwalitatief onderzoek. Om de leesbaarheid te bewaren, behandelen we de auteurs en de inhoud van de verschillende geïncludeerde artikelen (zie tabel 1 en de met een * gemarkeerde literatuur in de literatuurlijst) als respectievelijk deelnemers en data in een kwalitatief onderzoek en refereren we niet in de tekst, tenzij letterlijk geciteerd wordt. De inhoud van elk van de geïdentificeerde thema's is gebaseerd op het merendeel van de geïncludeerde artikelen. De verschillende thema's worden geillustreerd aan de hand van citaten uit de geïncludeerde artikelen. Om de betekenis van deze citaten niet te beïnvloeden, werden deze in de oorspronkelijke taal opgenomen.

Het eerste thema dat wordt besproken, 'de impact op de onderzoeker', betreft een algemeen thema over de emotionele impact van kwalitatief onderzoek op de onderzoeker en de gevolgen daarvan. Daarna volgen twee meer specifieke thema's: de onvoorspelbaarheid van kwalitatief onderzoek en de verschillende rollen van een onderzoeker. Deze twee thema's betreffen kenmerkende aspecten van kwalitatief onderzoek die reeds vaak (pragmatisch) zijn besproken in de literatuur. Uit de analyse van de data bleek dat deze aspecten van kwalitatief onderzoek een duidelijke invloed hebben op de emotionele beleving van kwalitatief onderzoekers. In deze bijdrage focussen wij dan ook op de emotionele aspecten die met deze eigenschappen van kwalitatief onderzoek gepaard gaan.

\section{De impact op de onderzoeker}

Onderzoekers erkennen dat het uitvoeren van kwalitatief onderzoek in het algemeen en in het bijzonder met betrekking tot kwetsbare groepen of gevoelige thema's, een diep emotionele ervaring en een emotioneel gebeuren is. De kenmerken van dergelijk kwalitatief onderzoek vragen een aanhoudende emotionele en fysieke inspanning van onderzoekers en laten een (al dan niet tijdelijke) emotionele impact na. 
'From this study and others, we can appreciate the emotionally difficult work that qualitative researchers undertake. The effect on researchers should not be underestimated.' (Moreno-Fergusson \& Grace, 2016: 63)

Veel onderzoekers rapporteren een gevoel van kwetsbaarheid als gevolg van een ervaren gebrek aan academische aandacht voor emoties verbonden aan kwalitatief onderzoek vanwege bijvoorbeeld docenten en supervisors in opleidingsprogramma's en tijdens wetenschappelijke werkzaamheden. Vaak leren zij pas door de literatuur te consulteren of door toevallige ontmoetingen en open gesprekken met collega-onderzoekers dat deze emoties inherent verbonden zijn aan kwalitatief onderzoek. Door eerlijk te zijn over hun gevoelens en hierover te publiceren willen de onderzoekers bewustzijn creëren omtrent het belang van emoties in kwalitatief onderzoek op ethisch, methodologisch en conceptueel-theoretisch vlak en/of omtrent het belang van het (h)erkennen van deze emoties voor de gezondheid en het welzijn van onderzoekers.

'To argue that emotions matter, and to write in a correspondingly open style, require a degree of vulnerability and trust that we will not be misread, our openness misunderstood or held against us by our readers.' (Kay \& Oldfield, 2011: 1279)

Hieronder beschrijven we de tijdelijke of blijvende veranderingen in (het leven van) de onderzoeker naar aanleiding van het onderzoeksproces en het veldwerk. De emotionele impact en de gevolgen daarvan kunnen gesitueerd worden op zowel het persoonlijke, het sociale als het professionele leven.

\section{Rollercoaster}

Op persoonlijk vlak wordt het uitvoeren van kwalitatief onderzoek omschreven als een 'roller coaster ride' (Beale, Cole, Hillege, McMaster \& Nagy, 2004: 146). Vooreerst ervaren onderzoekers een uitgebreide waaier van emoties zoals bezorgdheid, kwaadheid, verdriet, schaamte, frustratie en soms ook ongevoeligheid. Naast deze moeilijke of als negatief beschouwde emoties, ervaren onderzoekers ook positieve emoties bij kwalitatief onderzoek, zoals hoop, optimisme, energie en motivatie of plezier omtrent het uitvoeren van het onderzoek in het algemeen. Deze emoties komen dikwijls samen voor, waardoor ze als complex en tegenstrijdig worden ervaren. Verschillende onderzoekers hadden de intensiteit van de emoties niet verwacht, waardoor zij zich overspoeld voelen door de emoties die ze ervaren.

'The feelings and frustrations articulated by some patients left me with a mixture of emotions. As Coffey (1999) points out, fieldwork is about emotions: we have feelings about our research setting, people and experience. She goes on to say that we can and do feel joy, pain, hurt, excitement, anger, love, 
confusion, satisfaction, loss, happiness, and sadness, and this has certainly been my experience.' (Pellatt, 2003: 32)

'The interview process was rather paradoxical; I was often faced with a mix of feelings that simultaneously energized and drained me.' (Kumar \& Cavallaro, 2018: 5)

De ervaren emoties zijn verbonden met zowel het kwalitatief onderzoeksproces als de inhoud van het onderzoek. Enerzijds zijn de emoties een reactie op de aanhoudende emotionele en fysieke inspanning die kwalitatief onderzoek vraagt en het onvoorspelbare, unieke en iteratieve karakter ervan. Hierdoor wordt kwalitatief onderzoek ervaren als zwaar, moeilijk en als een uitdaging. Voorbeelden van emoties die hierbij worden ervaren, zijn frustratie over de tijdsinvestering die een kwalitatief onderzoek vraagt, opluchting of verdriet omdat het onderzoek afgerond werd, of gevoelens van trots op het onderzoek.

'Combined with academic concerns about ensuring the fieldwork was on schedule, if I was doing it right and if it was of sufficient quality, anxieties and feelings of insecurity rumbled disquietly alongside other personal emotional highs and lows during this period. These interrelated aspects of my social and professional life began to blur and worrying about the "bigger" picture of completing fieldwork, running out of time and concerns about finances, coupled with my emotional journeying through fieldwork, left me with an emotional hangover. These hangovers persisted in different ways with emotional and psychological feelings of disquiet and uneasiness lingering after the interview(s) had concluded, but also these segued into later stages of the research process.' (McGarrol, 2017: 440)

'Now looking back, I can see how important the work we did was. (...) I do not feel alienated when I think about the work that was done, but rather I am proud of it.' (Malacrida, 2007: 1338)

Anderzijds zijn de ervaren emoties een reactie op verhalen van deelnemers en gebeurtenissen in het veld waarmee onderzoekers geconfronteerd worden. Deze geven een inkijk in de meest intieme belevingen van mensen en zijn vaak doordrongen van onrechtvaardigheden en emotionele pijn. Deze onrechtvaardigheid, pijn, intimiteit, maar ook de veerkracht van deelnemers, laten een diepe emotionele indruk na bij onderzoekers.

'Over a 10-week period, I worked very closely with 16 older adults with Alzheimer's disease living in a long-term care facility and some of their family members. Those 10 weeks were anything but emotionless. At times I felt enraged and frustrated at the injustices being done to the residents and their family members.' (Dupuis, 1999: 50)

'I came out of the interview feeling a renewed burst of energy for life. On my way home in the car, I thought to myself "What an interesting phenomenon - 
that both of us had felt energized by our encounter!" [The respondent] was a powerful example of fighting life's hard deals, and her hunger to have her life back impressed me enormously.' (Scerri, Abela \& Vetere, 2012: 114)

De emotionele impact van kwalitatief onderzoek naar gevoelige onderwerpen is niet gebonden aan een specifieke periode in het onderzoek. Sommige onderzoekers ervaren de impact meteen bij de start van het veldwerk, terwijl andere onderzoekers eerder 'cumulative distress' ervaren (Woodby, Williams, Wittich \& Burgio, 2011: 833). Zij beseffen de impact pas op een later moment in het onderzoeksproces, bijvoorbeeld na het afnemen van meerdere interviews of tijdens het transcriberen, coderen of analyseren van de data, of (lange tijd) na het afronden van een onderzoeksproject.

\section{Impact op het sociale leven van de onderzoeker}

De kenmerken van kwalitatief onderzoek en de emoties die ermee gepaard gaan, hebben ook een invloed op het sociale leven van onderzoekers. Onderzoekers geven aan dat ze, door de flexibiliteit die ze aan de dag leggen, minder tijd hebben voor hun partners, familie en vrienden, en zich vaak eenzaam voelen. Daarnaast hebben de emoties die ze ervaren en de persoonlijke herinneringen die aan de oppervlakte komen soms een directe invloed op hun naasten en de relaties die ze met deze naasten hebben. Verder ervaren ze soms ook moeilijkheden om hetgeen ze mee- en doormaken tijdens kwalitatief onderzoek te delen met hun partners, familie, vrienden en collega's. Dit kan zijn omdat de ervaringen moeilijk te verwoorden zijn of omdat ze hun naasten niet willen belasten met deze ervaringen, of ze ervaren dat hun naasten en collega's geen interesse hebben in deze ervaringen.

'What I have come to realise is that embarking on this research, which I feel very strongly about both politically and academically, is not a process exclusive to myself. The research process impacts significantly on my family life, specifically on issues of intimacy in the relationship with my partner ...' (Sampson, Bloor \& Fincham, 2008: 926)

\section{Persoonlijke en professionele groei}

De ervaren emoties kunnen moeilijk los gezien worden van het privéleven van de onderzoekers. Onderzoekers beschrijven dat de ervaren emoties eigen (verdrongen) emoties of ervaringen oprakelen, of dat ze een angst ontwikkelen voor het zelf meemaken van de levensgebeurtenissen van deelnemers. Door de intensiteit van het onderzoeksproces bevragen onderzoekers zichzelf en hun leven op kritische wijze en worden ze geconfronteerd met hun persoonlijke angsten en kwetsbaarheden. Hoewel dit een moeilijk proces is, geven onderzoekers aan zaken te hebben geleerd over zichzelf of het leven en dat zij hierdoor een persoonlijke groei hebben doorgemaakt, veranderd zijn of op een andere manier in het leven staan. 
'While I find the situations that people are in quite upsetting and they often would bring me to tears as I am listening, they do on the other hand give me great respect for people who have to go through these very difficult times. I have become much less judgemental of people and the decisions they make, as I now realise that you just never know what is behind those decisions. That has been quite an attitude shift ... and I admire the strength of the people involved.' (Lalor, Begley \& Devane, 2006: 611)

Ook op de eigen mogelijkheden en vaardigheden als onderzoeker wordt gereflecteerd. De onderzoekers voelen zich onzeker, kwetsbaar en machteloos. Soms denken ze ernstig na over ontslag nemen. Deze twijfel en onzekerheid wordt vooral ervaren bij jonge onderzoekers of in het begin van een onderzoeksproject, maar blijft hier niet toe beperkt. Twijfel en onzekerheid komen ook voor bij meer ervaren onderzoekers of tijdens verdere fasen van een onderzoeksproject. Naarmate het onderzoeksproces vordert, bouwen onderzoekers echter vaak zelfvertrouwen op. Ze voelen zich meer comfortabel, meer competent en hebben meer controle over het onderzoeksproces. Ze hebben een beter gevoel bij hun mogelijkheden als wetenschappelijk onderzoeker of over de acties die ze ondernemen doorheen het onderzoeksproces.

'Maggie no longer needs any kind of interview schedule - not as a crutch for herself and not as a prop to display in front of her informants - to feel competent and professional. Not only does she now feel in control of the interviewing routine, she is even somewhat curious about deviating from the regular process, interpreting it as an "exercise." Towards the end of the research, Maggie completely jettisoned the index card and conducted her interviews in a much freer manner. Over time, then, we stopped relying on props and dress to make us look and feel professional, and became increasingly relaxed and self-confident in our abilities.' (Ibarra \& Kusenbach, 2001: 208)

\section{Emotioneel 'werk' en welzijn}

De emoties die onderzoekers ervaren noodzaken tot 'emotioneel werk'. Dit betekent dat onderzoekers een manier zoeken om aan de slag te gaan met deze emoties. Sommige onderzoekers trachten hun emoties te onderdrukken met als doel 'professioneel' blijven of tegemoetkomen aan verwachtingen van anderen over 'professioneel' gedrag, en het onderzoek voort te zetten. Andere onderzoekers gaan ertoe over deze emoties op een bewuste en kritische manier op te tekenen en te analyseren.

'I dealt with the relational dynamics by giving farmers space to show me their world and suppressing my own ideas, objections and emotions. This was my way of establishing emotional boundaries and coping with the violent relations on farms. ... When I returned from farm visits and wrote field notes, I often cried and once got so physically unwell that I vomited and I considered quitting. Only in my private space I allowed myself to feel the violent forms 
of appropriation and authority, including my ambivalent feelings towards my participation and complicity.' (Brandt \& Josefsson, 2017: 31)

Ondanks ditemotioneel werk kunnen de emotionele aspecten verbonden aan kwalitatief onderzoek afbreuk doen aan het lichamelijk en emotioneel welzijn van onderzoekers. Vaak schrijven onderzoekers over zowel lichamelijke als emotionele vermoeidheid en uitputting, met soms zelfs burn-out als gevolg. Andere voorbeelden zijn slapeloosheid en nachtmerries, concentratieproblemen, hoofdpijn, maag-darmproblemen en gewichtsverandering. Wat betreft het psychologisch welzijn geven verschillende onderzoekers aan dat zij blijven rumineren over de inhoud van het veldwerk. De verhalen die ze horen of de gebeurtenissen die ze meemaken, blijven in hun hoofd rondspoken. Sommige onderzoekers verwijzen hierbij naar secundaire traumatisering en andere onderzoekers vermelden ook (zelfgerapporteerde) depressieve gevoelens.

'We experienced researcher saturation - more commonly referred to as burnout - and gradually emotional overload led to our experience of distress: frequent headaches, anxiety and panic, a "foggy head," dizziness, nausea, and even a cyst on the vulva, reinforcing the embodied experience; exposure to fieldwork and personal life experience mediated individual responses of researchers.' (Wray, Markovic \& Manderson, 2007: 1397)

\section{De onvoorspelbaarheid van kwalitatief onderzoek}

Veel onderzoekers rapporteren specifiek over emoties die veroorzaakt worden door bepaalde onvoorspelbaarheden in het onderzoek. Zij brengen deze onverwachte emoties in verband met onwetendheid over en onvoldoende voorbereid zijn op de (heftige) emotionele impact van het onderzoek.

\section{Onvoorspelbaarheid onderzoek, ervaringen en emoties}

Enerzijds is deze onvoorspelbaarheid een element dat bijdraagt aan de intrinsieke interesse in het onderzoek. Het zorgt ervoor dat onderzoekers bij aanvang - maar ook doorheen het onderzoeksproces - constant geprikkeld worden door de nieuwe wereld waarin zij terecht zijn gekomen. Dit is vooral terug te vinden bij jonge onderzoekers of onderzoekers die een nieuw domein betreden, waarbij emoties als spanning, passie en euforie duidelijk worden waargenomen. Deze emoties vloeien vaak voort uit een onbevangenheid, enthousiasme en idealisme die zich kunnen uiten in een 'researcher high' (Diphoorn, 2013: 214) die wordt gekenmerkt door een niet-aflatende verhoogde productiviteit op het vlak van dataverzameling en -verwerking.

'And it was new, it was something I wasn't familiar with ... And I liked the experience and I liked learning about the lifestyle. I liked the people and I liked the context in which things took place.' (Sandberg \& Copes, 2013: 6) 
Anderzijds krijgen onderzoekers te maken met ervaringen en emoties tijdens het onderzoek die zij helemaal niet hadden voorzien. Dikwijls nemen zij zichzelf daarom een bepaalde vorm van naïviteit of zelfs arrogantie kwalijk en wel omdat zij overdreven vertrouwen stelden in een goede voorbereiding van het onderzoek. Het is immers niet mogelijk om te anticiperen op alle mogelijke onderzoekservaringen. Overigens, levenservaring en maturiteit van de onderzoeker lijken een adequate omgang met deze onverwachte situaties of emoties te bevorderen.

'I felt as though nothing had been thought out in advance ... and it was a question of feeling your way as you went ... I was just not prepared for some of the things that happened even though I thought I would be.' (Johnson \& Clarke, 2003: 425)

'I was naïve and arrogant to think I understood these challenges, and as such I did not properly prepare myself to engage in the needed self-care.' (Kumar \& Cavallaro, 2018: 6)

Er zijn verschillende onverwachte emoties tijdens het onderzoek die niet te voorspellen zijn alvorens het veld in te gaan. Dikwijls geven onderzoekers aan dat ze niet voorbereid waren op de grote impact die de verhalen of levens van deelnemers zouden hebben op hun persoon. Niet enkel de aanwezigheid van deze emoties werd als onverwacht ervaren, maar vooral ook de intensiteit waarmee deze aan de oppervlakte kwamen. Veel onderzoekers trachten zich voor te bereiden op deze emotionele impact en lijken zich op voorhand bewust van de mogelijke impact, maar de wijze waarop deze emoties effectief binnenkomen, wordt pas duidelijk wanneer het onderzoek uitgevoerd wordt.

'I totally underestimated the emotional [aspects] of it ... I was just stunned at how distressing it was and how heavy it was.' (Beale et al., 2004: 144)

'The intense emotions that came over me were unexpected and I had no idea where they came from. I was close to tears and could not really tell how that intense need to cry came about. I was not psychologically prepared and did not expect such emotions to occur.' (Pithouse-Morgan, Khau, Masinga \& Van de Ruit, 2012: 45)

Terwijl deze onderzoekers rapporteren over gevoelens van onmacht ten gevolge van de onvoorspelbaarheid van het onderzoek, wijzen andere onderzoekers op het uitblijven van de verwachte sterke emoties tijdens het veldwerk. Velen geven aan een soort ongevoeligheid te hebben ontwikkeld na het aanhoren van veel gelijkaardige ingrijpende verhalen.

'So when my friends and family, who knew me as a very emotional person, asked me "how are you managing such sad stories, isn't it really upsetting?" I actually answered - sincerely - that I was doing particularly well and that the 
stories were not affecting me in the way I thought they would.' (Benoot \& Bilsen, 2016: 4)

\section{Onvoorspelbaarheid tijdens het veldwerk}

De organisatie van het veldwerk en de praktische uitvoering ervan resulteren eveneens in onverwachte emoties. Hierbij gaat het over de overweldigende gevoelens die gepaard gaan met de constante druk bij het uitvoeren van het onderzoek. Onderzoekers uiten ook frustraties over het onvoorspelbare karakter van het veld en de bredere onderzoekssetting, waardoor de praktische organisatie van interviews en andere afspraken niet makkelijk verloopt.

'On a number of occasions I recorded frustration at the research process and in particular feelings of anger at respondents who had consistently cancelled on me.' (Browne, 2013: 426)

'The pace I desired was slower than my committee expected, and the pace of the interview schedule with my participants was much slower than I had hoped. I found myself feeling frustrated with my committee as well as my participants because, although I did not want to rush things along, I wanted to finish my dissertation.' (Huisman, 2008: 380)

Verder blijkt het contact zoeken met of het benaderen van deelnemers geen emotieloos proces te zijn. De druk van het succesvol volbrengen van het onderzoek kan ervoor zorgen dat een emotionele spanning ontstaat die blokkerend werkt of er zelfs toe kan leiden dat bepaalde facetten van het onderzoek niet of onvoldoende uitgevoerd worden.

'Sometimes I felt physically sick before phoning them ... it was like a minefield ... I didn't know what to expect ... I would put off making the calls and then I would pluck up the courage.' (Johnson \& Clarke, 2003: 425)

'Before trying to approach Maria, I was seized by worry, which turned into emotional tension as I considered that if my approach failed I might arouse suspicion, throwing away many months of work.' (Orsini, 2013: 342)

Bovendien brengt de ongerustheid over de fysieke veiligheid van onderzoekers sterke emoties met zich mee die resulteren in een gevoel van controleverlies, zowel over het onderzoek als over het eigen leven. Onderzoekers zoeken naar een evenwicht: enerzijds omgaan met gevoelens van onveiligheid en anderzijds het in stand houden van vertrouwensrelaties met deelnemers.

'When the deep night came I lay in bed terrified. This terror, unlike terror I had ever experienced before, overcame me. It hit me in waves. It was sharp, intense and consumed my whole body. I could feel every muscle in my body tense up. All of my reference points were gone. I lost my centre.' (Levy, 2016: 44) 
'I was more worried about quickly establishing a relationship trust with the family for the interview than my own safety.' (Bahn \& Weatherill, 2013: 26)

De emoties en reacties van deelnemers kunnen onverwacht en overweldigend overkomen bij de onderzoeker. Soms hebben deelnemers heel duidelijke hulpvragen waar onderzoekers niet mee weten om te gaan.

'So the main source of unease for me was the disclosure Jack made about his periodic consideration of suicide as an option should his dependence on others grow to be unacceptable to him. How should I think of the revelations he made? What should I do or say to him? How likely or near is the risk to him of this unresolved issue? What were my ongoing responsibilities?' (Moreno-Fergusson \& Grace, 2016: 60)

Ook tijdens andere fases van het onderzoek, zoals bijvoorbeeld het uitschrijven of coderen van de interviews, kunnen onverwachte emoties ervaren worden. Dikwijls betreffen het gevoelens van hulpeloosheid door het opnieuw beluisteren van de verhalen, zonder op dat moment te kunnen communiceren met de deelnemers. Ook het coderen van de data genereert reflectie op de eigen verrichtingen, wat gepaard kan gaan met gevoelens van onzekerheid.

'Transcribing 22.5 hours of interview recordings was the most challenging task during the entire research process. It was not the repetitive and mundane nature of the task that was difficult, but rather the fear of reliving coresearchers' pain or the anxiety of unresolved issues from my prior experiences of abuse.' (Kumar \& Cavallaro, 2018: 5)

\section{De verschillende rollen van een onderzoeker}

Onderzoekers worden op regelmatige basis geconfronteerd met de verschillende rollen die zij innemen. Deze rollen kunnen soms in strijd zijn met de identiteit die men zelf wenst of hoort in te nemen. Het ontstaan van dergelijke rolconflicten zorgt ervoor dat de onderzoeker in ongemakkelijke en emotionele situaties terechtkomt die potentieel van invloed zijn op zowel onderzoeker als deelnemers.

\section{Afstand en nabijheid}

Onderzoekers erkennen dat de band tussen hen en deelnemers cruciaal is. Door hun inspanningen om deze band intact te laten, ervaren ze (na een bepaalde tijd) verbondenheid en/of nabijheid met hun deelnemers. Ze staan heel dicht op de psychische en fysieke leefwereld van deelnemers en geven aan dat dit een emotionele prijs heeft. Veel onderzoekers ervaren namelijk angst en bezorgdheid vanwege de kwetsbaarheid van deelnemers en de vaak ingrijpende levensgebeurtenissen die zij meemaken. Deze emotionele en empathische band kan in sommige gevallen leiden tot 'compassion stress' (Rager, 2005: 426), het fenomeen waarbij onderzoekers gelijkaardige emoties ervaren als hun deelnemers. 
'The intimacy of the rapport which had developed between Ann and me transcended normal relational boundaries. I had not remained detached; I had become engaged with the story and personally involved. As a result, I was upset. Deeply upset.' (Fahie, 2014: 25)

'I started to internalize the bodily complaints my patients had, which means that I often literally could feel the pain symptoms or nausea from the patient I was interviewing at that time. Another consequence was that the fear of getting cancer myself grew with every interview I took.' (Benoot \& Bilsen, 2016: 5)

Vanwege het iteratief patroon van interacties, vooral tijdens longitudinaal en etnografisch onderzoek, kan deze verbondenheid en/of nabijheid behoorlijk intens zijn. Soms is deze intensiteit groter dan de onderzoekers verwacht hadden. Onderzoekers kunnen bijvoorbeeld een speciale band ontwikkelen met bepaalde deelnemers. Velen geven aan niet goed te weten hoe met deze emotionele binding om te gaan.

'There were moments when we felt powerfully attuned to the participant. These empathic experiences of sharing a particular feeling, seemingly as it was felt by the participant, connected us with them and we felt helped us understand (some of) their experience more fully.' (Boden, Gibson, Owen \& Benson, 2016: 4)

'I was aware that my very close relationship with Sarah was breaking the "feeling rules" (Hochschild, 1979).... However, I found that while my relationship with Sarah was more emotionally intense than I had expected, it also significantly expanded my knowledge about the nursery's practices.' (Blaisdell, 2015: 88)

Naast deze moeilijke emoties en de onzekerheid daarover, zorgt de verbondenheid en/of nabijheid met deelnemers tevens voor warme gevoelens bij onderzoekers, zoals plezier, tevredenheid, hoop, affectie en intimiteit. Ze voelen respect voor hun deelnemers, soms zelfs ontzag, en vinden het een privilege om met hen te kunnen werken.

'As a researcher, I felt privileged to be included in this insider talk and interaction.' (McQueeney \& Lavelle, 2017: 92)

Soms geven onderzoekers aan afstand te ervaren. Ze slagen er bijvoorbeeld niet of moeilijk in om een band te ontwikkelen. Omgekeerd, soms willen ze juist meer afstand creëren. Zo kunnen gevoelens van kwetsbaarheid ontstaan vanwege een ervaren outsider-status, waarbij de onderzoeker zichzelf zelfs bijna als indringer beschouwt. De gevolgen hiervan worden dikwijls op voorhand onvoldoende ingeschat, waardoor dit ongemakkelijke en soms zelfs contraproductieve situaties kan 
creëren. Deze emoties kunnen ook zorgen voor vreemd of ontwijkend gedrag bij de onderzoeker.

'The tension that hangs around Kim's disclosure underscores the uncertainty I experience as a researcher. On the one hand, I want to explore the issue of mothering such children, yet on the other hand, I feel like a trespasser in Kim's life as I expertly prompt her to expose the vulnerable layers of thoughts and feelings that she has buried for so long in self-protection.' (Emerald \& Carpenter, 2015: 3)

'I felt that they were oblivious to my presence but I was oh so conscious of mine and felt like an intruder. The whole setting felt sacred and I sat there thinking: what in the world am I doing here?' (Clancy, 2011: 115)

De confrontatie met de leefwereld van de deelnemers kan gevoelens van angst, frustratie, kwaadheid, walging en ambivalentie voortbrengen. Deze situatie doet zich voor als de attitudes en overtuigingen van deelnemers duidelijk verschillend zijn van deze van de onderzoeker. Hierdoor wordt een onderzoeker soms verplicht de eigen waarden en normen, overtuigingen en geloof, op de achtergrond te houden of zelfs te onderdrukken. Dit kan zich uiten in pijnlijke situaties, waarbij onderzoekers het gevoel hebben hun eigenheid en moraliteit te moeten verloochenen.

'As a feminist, I knew before I started the research that negotiating my ideological conflicts with the church's views would be a difficult dimension of my fieldwork. I did not, however, fully expect how painful this aspect of my fieldwork would be when having to deal with this conflict on a day-to-day basis for 16 months on the ground.' (Chong, 2008: 381)

'Interviewees often used racist and sexist language and I found it difficult to persevere with any kind of "rapport building" and objectivity under these conditions; on some level the richer the data became, the harder it was to stomach. ... I shifted between sympathy, revulsion, respect and contempt in the actual field.' (Bott, 2010: 167-168)

\section{Reciprociteit}

Verder gaat het voeren van onderzoek rond gevoelige onderwerpen ook dikwijls gepaard met schuldgevoelens bij het bevragen of observeren van kwetsbare personen in het kader van het verzamelen van onderzoeksgegevens. Onderzoekers ervaren dat de verhalen van deze mensen 'gebruikt' worden om te komen tot wetenschappelijke output en daarmee de eigen carrière bevorderen. De doelstellingen van dergelijk onderzoek zouden de beoogde doelgroep ten goede komen. Echter, vaak ervaren onderzoekers de 'voordelen' voor de deelnemers als te beperkt ten opzichte van hetgeen van hen gevraagd wordt. 
'As much as I wanted the relationship to be mutually beneficial, it was not. As much as I wanted to be on the same plane as my participants, this desire was overshadowed by the reality that I was doing this work in part to elevate my status and career.' (Huisman, 2008: 380)

Meerdere onderzoekers worstelen met deze vaststelling, waarbij het gevoel heerst dat de opgebouwde vertrouwensband met deelnemers instrumenteel gebruikt wordt om tegemoet te komen aan de academische doelstellingen.

'It would be hard for me to deny that my attempts to build rapport and gain his trust were underpinned by the instrumental purpose of persuading him to provide me with research data.' (Jewkes, 2012: 71)

'As I listened to some of these stories with my "researcher" ears, I became uncomfortable when I realized I was thinking "this is really good stuff" [...] I felt shocked that I might, even for one moment, lose my counsellor sensitivity.' (Sampson et al., 2008: 924)

Academisch werk is dikwijls werk van lange adem en mogelijk kunnen pas op lange termijn bepaalde voordelen voor de doelgroep bereikt worden. Dit zorgt voor twijfel over het nut van onderzoek en de academische werkzaamheden.

'[...] a belief that perhaps there really is little point in doing research at all when the needs of some people seem to be so pressing [...] The painstaking and lengthy process of actually doing social research is frustrating; that is, the distance between coding and producing any kind of social change is so wide that the chasm seems unbridgeable. (Malacrida, 2007: 1336)

'I wonder sometimes whether I am spending my career on a hopeless cause in which my efforts have no impact.' (Stahlke, 2018: 8)

Reciprociteit speelt ook een rol bij het afsluiten van het veldwerk. Enerzijds ervaren onderzoekers opluchting en rust. Anderzijds wordt het verlaten van de onderzoekssetting als moeilijk ervaren, ook wel omschreven als 'post-fieldwork blues' (Redman-MacLaren, 2015).

'I had expected that at the end of fieldwork I could walk out of these families' lives and proceed with my own, leaving them to get on with theirs; after all, I had accomplished my aim. On the contrary: Leaving the participants was not easy. I wanted to maintain contact with the families, and I did not want to be seen as a stranger who came into their lives for a short period of time, got what she wanted, and moved on.' (Ochieng, 2010: 1733)

Enkele etnografisch onderzoekers wijzen echter op een afnemende intensiteit van emoties naarmate het einde van het veldwerk in zicht komt. 
'I was partly relieved when some of the more emotionally challenging interviews were over.' (Petty, 2017: 28)

Het afronden van onderzoeksrapporten kan gepaard gaan met (onverwachte) vormen van teleurstelling. Zo kan soms een gevoel van onmacht en schuld ontstaan wanneer het verhaal van een deelnemer niet volledig weergegeven kan worden.

'After reading the draft of the second report for ACC I felt disappointed that more details of the residents' negative experiences had not been included. [...] I still felt guilty that I had not been able to represent these householders in the way I would have liked but had to be satisfied that I had tried to get their voice heard and had succeeded to some extent.' (McKenzie, 2017: 8)

\section{Verwachtingen over in te nemen positie als onderzoeker}

De sterke verbondenheid tussen onderzoeker en deelnemers wekt verwachtingen over de houding die de onderzoeker inneemt of dient in te nemen. Nu trachten onderzoekers in de eerste plaats hun objectiviteit te bewaren, maar deze professionele norm is niet steeds makkelijk te bewaren. De precaire situaties waarin veel deelnemers verkeren en de soms pijnlijke verhalen die gedeeld worden, zorgen ervoor dat onderzoekers dikwijls het gevoel hebben een eerder hulpverlenende rol te moeten innemen om op die manier het lijden van deelnemers op korte termijn te helpen verzachten. De wetenschap dat het innemen van deze rol eigenlijk niet past bij de rol van onderzoeker kan voor veel ongemak zorgen.

'In the researcher role at times one felt helpless, as all he could do was listen.' (Newman, O’Reilly, Lee \& Kennedy, 2017: 12)

Het is dan ook niet evident dat onderzoekers deze hulpverlenende rol op zich nemen, zeker wanneer zij niet als hulpverlener zijn opgeleid. Echter, ook voor sociale wetenschappers die opgeleid zijn als hulpverleners (zoals sociaal werkers en verplegers) creëert het samenspel van rollen dikwijls moeilijke en verwarrende emoties.

'As the interviewer, I experienced feelings of powerlessness and frustration. In my role as a researcher rather than as a therapist, it was difficult to resolve her concerns or ameliorate her distress.' (Woodby et al., 2011: 831)

De focus van sociale interactie is voor een hulpverlener of therapeut duidelijk anders dan voor een onderzoeker. Ook de manier waarop sociale interactie aangegaan wordt, verschilt en kan een duidelijke emotionele impact op de onderzoeker hebben.

'This may say something about the way I have worked as a practitioner - always busy, talking to patients on a fairly superficial level - and for the first time, actually sitting down and listening to patients for up to an hour. 
When I trained more than 35 years ago we were told "not to get involved" and to suppress our feelings.' (Pellatt, 2003: 32)

'You're not there as a social worker ... you're there as a researcher and that feels very different ... there's no professional distance, no expectations that you're there to help. I had the knowledge to offer much more. I felt de-skilled, useless ... sometimes it went against what I went into social work for.' (Davison, 2004: 385)

Dit rolconflict tussen hulpverlenen en onderzoeken brengt dikwijls intense emoties met zich mee. Een evenwicht vinden tussen deze twee rollen vormt vaak een persoonlijke zoektocht. Dit rolconflict speelt overigens niet alleen bij onderzoekers. De deelnemers koesteren namelijk ook bepaalde verwachtingen van onderzoekers. Soms ontstaan bepaalde vriendschappelijke banden met de onderzoeker, doordat deelnemers zoveel persoonlijke informatie delen. Dit zorgt ervoor dat een zekere ongelijkheid in verwachtingen over het onderzoek ontstaat tussen deelnemer en onderzoeker. Voor deze laatste kan dit zelfs aanvoelen als een vorm van verraad, gepaard met schuldgevoelens ten opzichte van deelnemers.

'However, because of the intimacy of ethnographic methods and cultural differences that I will examine in more detail below, many participants, particularly women, viewed me as a friend, and a few even referred to me as a member of their family. Thus, the boundaries were blurred, and this exacerbated my concerns about betrayal.' (Huisman, 2008: 380)

Het ontstaan van dergelijke vriendschapsbanden zorgt niet enkel voor veel twijfel bij onderzoekers, maar zorgt er ook voor dat de gevoelde druk opgevoerd wordt.

"There is a fear of disappointing expectations, of "letting a friend down"; the dreadful feeling of leaving without having "resolved" the fieldworker-subject relationship.' (Ibarra \& Kusenbach, 2001: 213)

Daarnaast wekt het vervagen van de grens tussen onderzoeker en vriend verwachtingen bij deelnemers over toekomstig contact die onmogelijk ingelost kunnen worden. Deze verwachtingen zorgen voor pijnlijke situaties.

'An extremely difficult situation can emerge when the researcher feels a conflict of interest has arisen and that either they have moved beyond the boundary of research or the participant seeks to engage further with the researcher.' (Moyle, 2002: 272)

\section{Situaties van ongelijke machtsverhoudingen}

De geschetste ongelijke machtsverhouding heeft op verschillende manieren een impact op de onderzoeker. Vaak ontstaan situaties waarbij onderzoekers een machtige positie innemen. Dat uit zich door de intrinsiek kwetsbare situatie waarin deelnemers zich bevinden - waarin zij veel van hun ervaringen vrijgeven - 
zonder dat dit een volledig wederzijdse relatie is waarbij ook de onderzoeker persoonlijke informatie deelt. Dit maakt bij de laatste gevoelens van angst, schuld en oneerlijkheid los.

'The power imbalance implicit in these disparities generated not only personal, but also professional, ethical anxieties to do with the exploitative implications of hierarchical research relations.' (Bott, 2010: 165)

'Early in the data collection phase, the researcher experienced profound feelings of indebtedness to the informants.' (Cartwright \& Limandri, 1997: 227)

Daarnaast zorgt de kwetsbare situatie van deelnemers voor ongemak vanwege de duidelijk bevoorrechte positie waarin onderzoekers verkeren.

'How can I not compensate them? They are poor, helpless. They ask for imdaad (charity). How can I refuse? My life and theirs are so different.' (Anwar \& Viqar, 2017: 118)

Deze verhoudingen blijken zeker niet stabiel te zijn doorheen het volledige onderzoeksproces. Onderzoekers voelen zich afhankelijk van deelnemers voor het verkrijgen van data. Ze ervaren ook dat deelnemers de bestaande machtsverhoudingen trachten om te keren door hen - soms systematisch - uit te dagen tijdens het onderzoek. Hierbij gaat het over al dan niet discriminatoire situaties waarbij onderzoekers het gevoel krijgen geïntimideerd, gestigmatiseerd of geseksualiseerd te worden. Deze situaties kunnen bij onderzoekers gepaard gaan met gevoelens van kwetsbaarheid, eenzaamheid en onzekerheid.

'I was also laughed at and propositioned indirectly. There were a number of instances where men have told me "I would love to be harassed in the workplace" or "aren't you interviewing us on this very interesting subject" "I, of course, love to be harassed a little by a lady in the office." [...] I also felt very vulnerable, self-conscious and anxious being faced with these experiences, even though I was actually researching the same experiences (sexual harassment) of others.' (Adikaram, 2018)

\section{Discussie en conclusie}

Het doel van deze bijdrage is een (niet-exhaustief) beknopt overzicht geven van de emotionele beleving van kwalitatief onderzoek en op deze manier meer structurele en proactieve aandacht en bewustzijn creëren voor de emotionele aspecten die verbonden zijn aan het verrichten van kwalitatief onderzoek. Om deze doelstelling te bereiken, hebben wij op systematische wijze een literatuurstudie uitgevoerd waarbij wij op zoek gingen naar (auto-etnografische) onderzoeksbevindingen over de emotionele beleving van kwalitatief onderzoek naar kwetsbare personen of gevoelige thema's. 
In het algemeen leerde deze literatuurstudie ons, net zoals onderzoekers vóór ons, dat empirisch onderzoek naar de ervaringen van onderzoekers en onderzoeksgroepen met emotionele aspecten van onderzoek en naar de consequenties van deze emoties voor de onderzoeker, de onderzoeksgroep en het onderzoek zelf, weinig voorhanden is (zie bijvoorbeeld Davison, 2004; Dickson-Swift, James, Kippen \& Liamputtong, 2009; Johnson \& Clarke, 2003; Pollard, 2009). In de literatuur kan men wel wetenschappelijke artikelen, hoofdstukken en (hand)boeken vinden waarin de bevindingen van auto-etnografisch onderzoek met betrekking tot de emotionele beleving van kwalitatief onderzoek worden weergegeven. Naast de pragmatische bespreking van typische aspecten verbonden aan kwalitatief onderzoek zoals rolconflicten, politieke en ethische misstanden, het bekomen van toegang tot een onderzoekspopulatie, veiligheid van onderzoekers, informanten en deelnemers, wordt in deze publicaties ook diepgaand ingegaan op de emotionele impact van deze aspecten (zie, naast de geïncludeerde artikelen, bijvoorbeeld Allan \& Arber, 2018; Beyens et al., 2013; Kleinman \& Copp, 1993; Nordstrom \& Robben, 1995; Sriram, King, Mertus, Martin-Ortega \& Herman, 2009). De bespreking van emotionele aspecten die gepaard kunnen gaan met kwalitatief onderzoek ontbreekt echter grotendeels in academische (doctoraats)opleidingen en in klassieke handboeken over kwalitatief onderzoek (Beyens, 2013; Davies \& Spencer, 2010; Pollard, 2009; Velardo \& Elliot, 2018).

Op inhoudelijk vlak kunnen de bevindingen van deze literatuurstudie op basis van de 82 geïncludeerde artikelen als volgt samengevat worden. Kwalitatief onderzoekers kunnen een brede waaier van pijnlijke - maar ook positieve - emoties ervaren voor, tijdens en na het veldwerk. Deze emoties hebben zowel te maken met de procesmatige kenmerken van kwalitatief onderzoek, namelijk het langdurige, intense en onvoorspelbare veldwerk en de actieve en subjectieve positie van de onderzoeker waar verschillende rollen mee gepaard kunnen gaan, als met de inhoudelijke kenmerken van hun kwalitatief onderzoek, zoals de onderdompeling in de subjectieve en fysieke leefwereld van (kwetsbare) personen die ingrijpende levensgebeurtenissen hebben meegemaakt, en de machtspositie van de onderzoeker. Vaak worden verschillende (on)aangename emoties tegelijkertijd ervaren, waardoor onderzoekers in een emotionele achtbaan kunnen terechtkomen. Het geheel aan emoties heeft een impact op het persoonlijke en sociale leven van kwalitatief onderzoekers, alsmede op hun professionaliteit. Hoewel soms een persoonlijke groei wordt beschreven, vermelden onderzoekers ook uitputting, problemen met de lichamelijke gezondheid, problemen met het emotioneel welzijn en burn-out.

In tegenstelling tot de idiosyncratische ervaringen omtrent de emotionele beleving van kwalitatief onderzoek, maken zo goed als alle onderzoekers melding van het gebrek aan aandacht en bewustzijn voor deze emoties in de academische wereld, en dit zowel in hun (doctoraats)opleiding als tijdens de supervisie van hun veldwerk. Tijdens het veldwerk voelen ze zich dikwijls onvoldoende voorbereid op de emotionele impact van kwalitatief onderzoek naar kwetsbare groepen en gevoelige thema's. Terwijl individuele onderzoekers en onderzoeksgroepen reeds lange tijd bekend zijn met de emotionele aspecten en moeilijkheden verbonden met kwalitatief onderzoek naar kwetsbare personen of gevoelige thema's en daar- 
over publiceren, lijkt dit besef niet door te dringen tot het structureel institutioneel niveau. Dat brengt het risico met zich mee enkel reactief aan de slag te gaan met de emotionele aspecten van kwalitatief onderzoek in plaats van proactief na te denken over het omgaan met emoties tijdens kwalitatief onderzoek op zowel persoonlijk als methodologisch-theoretisch niveau.

Het is opvallend dat de gezondheidswetenschappen de meest voorkomende discipline is binnen de geïncludeerde artikelen. Deze vaststelling kan te maken hebben met een grotere aandacht voor het publiceren over emoties binnen dit wetenschapsdomein of met de kenmerken van ons literatuuronderzoek, met name de twee doorzochte databanken. Ook binnen de criminologische onderzoeksdiscipline mag meer bewustzijn en aandacht komen voor de emotionele impact van kwalitatief onderzoek (zie ook Beyens et al., 2013). De spaarzame emotionele reflecties op detentieonderzoek kunnen tot voorbeeld dienen voor onderzoekers die andere criminologische onderzoeksthema's bestuderen. Daarnaast is het merendeel van de auteurs van de geïncludeerde bijdragen vrouw. Het is mogelijk dat vrouwen meer aandacht hebben voor emotionele aspecten van kwalitatief onderzoek. Crewe (2014) betwijfelt dit echter.

Emoties zijn inherent verbonden aan kwalitatief onderzoek (Gilbert, 2000; Mazzetti, 2018). Daarom willen wij afsluitend enkele manieren bespreken waarop kan omgegaan worden met de emotionele impact van kwalitatief onderzoek vanuit eerste persoonsperspectief. Hiervoor kan gebruikgemaakt worden van het 'conceptual framework of researcher selfcare in emotionally demanding research' van Kumar en Cavallaro (2018: 8). In dit conceptueel kader wordt een individuele en institutionele aanpak als gelijkwaardig beschouwd. Op institutioneel niveau kunnen ethische commissies en (doctorale) opleidingsprogramma's meer aandacht hebben voor de emotionele impact op onderzoekers naast de aandacht die bestaat voor de impact op deelnemers. Onderzoekers en onderzoeksgroepen kunnen hierop attent gemaakt worden en gemotiveerd worden na te denken over strategieën om hiermee om te gaan (Bahn \& Weatherill, 2013; Benoot \& Bilsen, 2016; Boden et al., 2016; Pollard, 2009; Velardo \& Elliot, 2018). Op het niveau van de onderzoeksgroep zijn supervisie en intervisie belangrijk. Onderzoekers moeten de mogelijkheid krijgen om te debriefen over hun ervaringen tijdens het veldwerk zowel tijdens formele als tijdens informele overlegmomenten met senior onderzoekers en supervisors. Een ondersteunende academische cultuur is hierbij een voorwaarde (Fahie, 2014; Johnson \& Clarke, 2003; Kennedy, Hicks \& Yarker, 2014). Ook formele en informele intervisiemomenten met collega-onderzoekers worden in deze optiek als positief ervaren (Beale et al., 2004; DicksonSwift, James, Kippen \& Liamputtong, 2006; Evans, McCarthy, Bowlby, Wouango \& Kebe, 2017). Daarnaast moet de onderzoeker voldoende mogelijkheden hebben om zich terug te trekken van het veldwerk, bijvoorbeeld voldoende pauze, vakantie en afwisseling tussen veldwerk en bureauwerk, zodat de onderzoeker tijd en ruimte krijgt om emotionele ervaringen een plaats te geven (Cartwright \& Limandri, 1997; Diphoorn, 2013; Ibarra \& Kusenbach, 2001). Op individueel niveau dient een onderzoeker voldoende aandacht te besteden aan de voorbereiding van het veldwerk door bijvoorbeeld grondig methodologisch in te lezen op het veldwerk, na te denken over mogelijke persoonlijke grenzen, risico's en problemen, 
advies te vragen aan collega-onderzoekers en persoonlijke strategieën voor zelfzorg te bedenken (Boden et al., 2016; deMarrais \& Tisdale, 2002; Horton, 2008; Pesonen, Remes \& Isola, 2011). Een sluitende voorbereiding is echter een utopie. Blijvende aandacht voor deze zaken tijdens en na het veldwerk, door middel van een onderzoeksdagboek en regelmatige overlegmomenten, is noodzakelijk om emotionele ervaringen en de impact die deze hebben tastbaar te maken (Adams \& Manning, 2015; Nilson, 2017). Naast een professioneel netwerk, kan een sociaal netwerk ook een rol spelen in de ondersteuning van een onderzoeker (Kumar \& Cavallaro, 2018).

\section{Literatuur}

Adams, E. (2010). The joys and challenges of semi-structured interviewing. Community Practitioner, 83(7), 18-21.

Adams, T.E. \& Manning, J. (2015), Autoethnography and family research. Journal of Family Theory and Review, 7(4), 350-366.

Adikaram, A.S. (2018). Being sensitive to the culture: challenges in researching sensitive topics in an Asian culture. Qualitative Research Journal, 18(3), 287-299.

Allan, H. \& Arber, A. (2018). Emotions and reflexivity in health and social care field research. Cham: Palgrave Macmillan.

Anwar, N.H. \& Viqar, S. (2017). Research assistants, reflexivity and the politics of fieldwork in urban Pakistan. Area, 49(1), 114-121.

Bahn, S. \& Weatherill, P. (2013). Qualitative social research: a risky business when it comes to collecting 'sensitive' data. Qualitative Research, 13(1), 19-35.

Bashir, N. (2018). Doing research in peoples' homes: fieldwork, ethics and safety - on the practical challenges of researching and representing life on the margins. Qualitative Research, 18(6), 638-653.

Beale, B., Cole, R., Hillege, S., McMaster, R. \& Nagy, S. (2004). Impact of in-depth interviews on the interviewer: roller coaster ride. Nursing and Health Sciences, 6(2), 141-147.

Bell, A.S., Rajendran, D. \& Theiler, S. (2012). Job stress, wellbeing, work-life balance and work-life conflit among Australian academics. E-Journal of Applied Psychology, 8(1), 25-37.

Benoot, C. \& Bilsen, J. (2016). An auto-ethnographic study of the disembodied experience of a novice researcher doing qualitative cancer research. Qualitative Health Research, 26(4), 482-489.

Beyens, K. (2013). Introduction. Giving voice to the researcher. In: K. Beyens, J. Christiaens, B. Claes, S. De Ridder, H. Tournel \& H. Tubex (Eds.), The pains of doing criminological research (p. 13-21). Brussel: VUB Press.

Beyens, K., Christiaens, J., Claes, B., De Ridder, S., Tournel, H. \& Tubex, H. (2013). The pains of doing criminological research. Brussel: VUB Press.

Blaisdell, C. (2015). Putting reflexivity into practice: experiences from ethnographic fieldwork. Ethics and Social Welfare, 9(1), 83-91.

Boden, Z. V.R., Gibson, S., Owen, G.J. \& Benson, O. (2016). Feelings and intersubjectivity in qualitative suicide research. Qualitative Health Research, 26(8), 1078-1090.

Bott, E. (2010). Favourites and others: Reflexivity and the shaping of subjectivities and data in qualitative research. Qualitative Research, 10(2), 159-173. 
Brandt, F. \& Josefsson, J. (2017). Sexuality and power on South African game farms; reflections on positionality and emotions in ethnographic research. Emotion Space and Society, 23, 26-32.

Browne, B.C. (2013). Recording the personal: the benefits in maintaining research diaries for documenting the emotional and practical challenges of Fieldwork in Unfamiliar Settings. International Journal of Qualitative Methods, 12, 420-435.

Butler, A.E., Copnell, B. \& Hall, H. (2019). Researching people who are bereaved: Managing risks to participants and researchers. Nursing Ethics, 26(1), 224-234.

Caretta, M.A. \& Jokinen, J.C. (2017). Conflating privilege and vulnerability: A reflexive analysis of emotions and positionality in postgraduate fieldwork. Professional Geographer, 69(2), 275-283.

Carroll, K. (2013). Infertile? The emotional labour of sensitive and feminist research methodologies. Qualitative Research, 13(5), 546-561.

Cartwright, J. \& Limandri, B. (1997). The challenge of multiple roles in the qualitative clinician researcher-participant client relationship. Qualitative Health Research, 7(2), 223-235.

Case, A.D. (2017). Reflexivity in counterspaces fieldwork. American Journal of Community Psychology, 60(3-4), 398-405.

Chong, K.H. (2008). Coping with conflict, confronting resistance: Fieldwork emotions and identity management in a South Korean evangelical community. Qualitative Sociology, 31(4), 369-390.

Clancy, A. (2011). An embodied response: Ethics and the nurse researcher. Nursing Ethics, 18(1), 112-121.

Cooke, A., Smith, D. \& Booth, A. (2012). Beyond PICO: the SPIDER tool for qualitative evidence synthesis. Qualitative Health Research, 22(10), 1435-1443.

Crewe, B. (2014). Not looking hard enough: Masculinity, emotion, and prison research. Qualitative Inquiry, 20(4), 392-403.

Damsa, D. \& Ugelvik, T. (2017). A difference that makes a difference? Reflexivity and researcher effects in an all-foreign prison. International Journal of Qualitative Methods, 16(1), 10.

Davies, J. (2010). Introduction. In: J. Davies \& D. Spencer (Eds.), Emotions in the field. The Psychology and Anthropology of Fieldwork Experience (p. 1-31). Stanford: Stanford University Press.

Davison, J. (2004). Dilemmas in research: Issues of vulnerability and disempowerment for the social worker/researcher. Journal of Social Work Practice, 18(3), 379-393.

deMarrais, K. \& Tisdale, K. (2002). What happens when researchers inquire into difficult emotions?: Reflections on studying women's anger through qualitative interviews. Educational Psychologist, 37(2), 115-123.

Dickson-Swift, V., James, E.L., Kippen, S. \& Liamputtong, P. (2006). Blurring boundaries in qualitative health research on sensitive topics. Qualitative Health Research, 16(6), 853-871.

Dickson-Swift, V., James, E.L., Kippen, S. \& Liamputtong, P. (2009). Researching sensitive topics: Qualitative research as emotion work. Qualitative Research, 9(1), 61-79.

Dijk, D. van (2015). Mission impossible: Not getting emotionally involved in research among vulnerable youth in South Africa. Contributions from European Symbolic Interactionists: Reflections on Methods, 44, 61-77.

Diphoorn, T. (2013). The emotionality of participation: Various modes of participation in ethnographic fieldwork on private policing in Durban, South Africa. Journal of Contemporary Ethnography, 42(2), 201-225. 
Drake, D.H. \& Harvey, J. (2014). Performing the role of ethnographer: processing and managing the emotional dimensions of prison research. International Journal of Social Research Methodology, 17(5), 489-501.

Dupuis, S.L. (1999). Naked truths: Towards a reflexive methodology in leisure research. Leisure Sciences, 21(1), 43-64.

Emerald, E. \& Carpenter, L. (2015). Vulnerability and emotions in research: Risks, dilemmas, and doubts. Qualitative Inquiry, 21(8), 741-750.

Evans, R., McCarthy, J.R., Bowlby, S., Wouango, J. \& Kebe, F. (2017). Producing emotionally sensed knowledge? Reflexivity and emotions in researching responses to death. International Journal of Social Research Methodology, 20(6), 585-598.

Fahie, D. (2014). Doing sensitive research sensitively: Ethical and methodological issues in researching workplace bullying. International Journal of Qualitative Methods, 13, 19-36.

Gabriel, L., James, H., Cronin-Davis, J., Tizro, Z., Beetham, T., Hullock, A. \& Raynar, A. (2017). Reflexive research with mothers and children victims of domestic violence. Counselling and Psychotherapy Research, 17(2), 157-165.

Gilbert, K.R. (2000). Introduction: why are we interested in emotions. In: K.R. Gilbert (Ed.), The emotional nature of qualitative research (p. 3-15). Florida: CRC Press.

Hammersley, M. (2013). Methodological philosophies. In: M. Hammersley (Ed.), What is qualitative research (p. 21-46). Londen: Bloomsbury Academic.

Harris, M. (2015). 'Three in the room': Embodiment, disclosure, and vulnerability in qualitative research. Qualitative Health Research, 25(12), 1689-1699.

Holland, J. (2007). Emotions and research. International Journal of Social Research Methodology, 10, 195-209.

Horton, J. (2008). A 'sense of failure'? Everydayness and research ethics. Childrens Geographies, 6(4), 363-383.

Huijsmans, R. (2018). 'Knowledge that moves': emotions and affect in policy and research with young migrants. Childrens Geographies, 16(6), 628-641.

Huisman, K. (2008). 'Does this mean you're not going to come visit me anymore?': An inquiry into an ethics of reciprocity and positionality in feminist ethnographic research. Sociological Inquiry, 78(3), 372-396.

Ibarra, P.R. \& Kusenbach, M. (2001). Feeling the field: Tracking shifts in ethnographic research. Studies in Symbolic Interaction, 24, 195-221.

Jewkes, Y. (2012). Autoethnography and emotion as intellectual resources: Doing prison research differently. Qualitative Inquiry, 18(1), 63-75.

Johnson, N. (2009). The role of self and emotion within qualitative sensitive research: a reflective account. Enquire, 2(2), 191-214.

Johnson, B. \& Clarke, J.M. (2003). Collecting sensitive data: The impact on researchers. Qualitative Health Research, 13(3), 421-434.

Kay, R. \& Oldfield, J. (2011). Emotional engagements with the field: A view from area studies. Europe-Asia Studies, 63(7), 1275-1293.

Kendall, M., Harris, F., Boyd, K., Sheikh, A., Murray, S. A., Brown, D., et al. (2007). Key challenges and ways forward in researching the 'good death': Qualitative in-depth interview and focus group study. BMJ, 334(7592), 521.

Kennedy, F., Hicks, B. \& Yarker, J. (2014). Work stress and cancer researchers: An exploration of the challenges, experiences and training needs of UK cancer researchers. European Journal of Cancer Care, 23(4), 462-471.

Klein, J.L., Bailey, D.J.S. \& Sample, L.L. (2018). Researching the registered: Challenges and suggestions for researchers studying sex offender populations. Criminal Justice Studies, 31(2), 192-211. 
Kleinman, S. \& Copp, M.A. (1993). Emotions and fieldwork. Qualitative research methods series 28. California: Sage Publications, Inc.

Kumar, S. \& Cavallaro, L. (2018). Researcher self-care in emotionally demanding research: A proposed conceptual framework. Qualitative Health Research, 28(4), 648-658.

Lalor, J.G., Begley, C.M. \& Devane, D. (2006). Exploring painful experiences: impact of emotional narratives on members of a qualitative research team. Journal of Advanced Nursing, 56(6), 607-616.

Levecque, K., Anseel, F., De Beuckelaer, A., Van der Heyden, J. \& Gisle, L. (2017). Work organization and mental health problems in PhD students. Research Policy, 46(4), 868-879.

Levy, N. (2016). Emotional landscapes: Discomfort in the field. Qualitative Research Journal, 16(1), 39-50.

Lincoln, Y.S. \& Guba, E.G. (1985). Naturalistic inquiry. Newbury Park, CA: Sage Publications.

Lumsden, K. (2013). Survival of the fastest: Ethical dilemmas in research with 'boy racers'. Young, 21(3), 273-288.

Madziva, R. (2015). A gift exchange relationship? Reflections on doing qualitative research with vulnerable migrants. Families Relationships and Societies, 4(3), 465-480.

Malacrida, C. (2007). Reflexive journaling on emotional research topics: Ethical issues for team researchers. Qualitative Health Research, 17(10), 1329-1339.

Marshall, L. \& Morris, C. (2011). Taking wellbeing forward in higher education. Brighton: University of Brighton Press.

May, T. \& Perry, B. (2017). Reflexivity. The essential guide. Londen: Sage Publication Ltd.

Mazetti, A.S. (2018). The emotional nature of qualitative Research. In: M. Ciesielska \& D. Jemielniak (Eds.), Qualitative methodologies in organization studies (p. 159-171). Cham: Palgrave Macmillan.

McGarrol, S. (2017). The emotional challenges of conducting in-depth research into significant health issues in health geography: Reflections on emotional labour, fieldwork and life course. Area, 49(4), 436-442.

McKenzie, J.S. (2017). Emotional reflexivity and the guiding principle of objectivity in an inter-disciplinary, multi-method, longitudinal research project. Sociological Research Online, 22(1), 13.

McQueeney, K. \& Lavelle, K.M. (2017). Emotional labor in critical ethnographic work: In the field and behind the desk. Journal of Contemporary Ethnography, 46(1), 81-107.

Moreno-Fergusson, M.E. \& Grace, P.J. (2016). Ethical analysis of a qualitative researcher's unease in encountering a participant's existential ambivalence. Annual Review of Nursing Research, 34, 51-65.

Mortelmans, D. (2013). Handboek kwalitatieve onderzoeksmethoden. Leuven/Den Haag: Acco.

Mosavel, M., Ahmed, R., Daniels, D. \& Simon, C. (2011). Community researchers conducting health disparities research: Ethical and other insights from fieldwork journaling. Social Science and Medicine, 73(1), 145-152.

Moyle, W. (2002). Unstructured interviews: Challenges when participants have a major depressive illness. Journal of Advanced Nursing, 39(3), 266-273.

Newman, D., O'Reilly, P., Lee, S.H. \& Kennedy, C. (2017). Challenges in accessing and interviewing participants with severe mental illness. Nurse Researcher, 25(1), 37-42.

Nielsen, M.M. (2010). Pains and possibilities in prison on the use of emotions and positioning in ethnographic research. Acta Sociologica, 53(4), 307-321.

Nilson, C. (2017). A journey toward cultural competence: The role of researcher reflexivity in indigenous research. Journal of Transcultural Nursing, 28(2), 119-127. 
Norander, S. (2017). Embodied moments: Revisiting the field and writing vulnerably. Journal of Applied Communication Research, 45(3), 346-351.

O'Connor, S.J. (2011). Context is everything: The role of auto-ethnography, reflexivity and self-critique in establishing the credibility of qualitative research findings. European Journal of Cancer Care, 20(4), 421-423.

Ochieng, B.M.N. (2010). 'You know what I mean:' The ethical and methodological dilemmas and challenges for black researchers interviewing black families. Qualitative Health Research, 20(12), 1725-1735.

Orsini, A. (2013). A day among the diehard terrorists: The psychological costs of doing ethnographic research. Studies in Conflict and Terrorism, 36(4), 337-351.

Pellatt, G. (2003). Ethnography and reflexivity: Emotions and feelings in fieldwork. Nurse Researcher, 10(3), 28-37.

Pesonen, H.M., Remes, A.M. \& Isola, A. (2011). Ethical aspects of researching subjective experiences in early-stage dementia. Nursing Ethics, 18(5), 651-661.

Petty, J. (2017). Emotion work in qualitative research: interviewing parents about neonatal care. Nurse Researcher, 25(3), 26-30.

Pithouse-Morgan, K., Khau, M., Masinga, L. \& Ruit, C. van de (2012). Letters to those who dare feel: Using reflective letter-writing to explore the emotionality of research. International Journal of Qualitative Methods, 11(1), 40-56.

Pollard, A. (2009). Field of screams: difficulty and ethnographic fieldwork. Anthropology Matters, 11(2), 1-24.

Rager, K.B. (2005). Compassion stress and the qualitative researcher. Qualitative Health Research, 15(3), 423-430.

Raheim, M., Magnussen, L.H., Sekse, R.J., Lunde, A., Jacobsen, T. \& Blystad, A. (2016). Researcher-researched relationship in qualitative research: Shifts in positions and researcher vulnerability. International Journal of Qualitative Studies of Health Wellbeing, 11, 30996.

Redman-MacLaren, M. (2015). Becoming a researcher: An auto-ethnographic account of a doctoral researcher re-presented in poetry. Journal of Poetry Therapy, 28(3), 207-214.

Riley, R. \& Weiss, M.C. (2016). A qualitative thematic review: emotional labour in healthcare settings. Journal of Advanced Nursing, 72(1), 6-17.

Robben, A.C.G.M. \& Nordstrom, C. (1995). Introduction. The anthropology and ethnography of violence and sociopolitical conflict. In: C. Nordstrom \& A.C.G.M. Robben (Eds.), Fieldwork under fire. Contemporary studies of violence and survival (p. 1-23). California: University of California Press.

Rodriguez, L. (2018). Methodological challenges of sensitive topic research with adolescents. Qualitative Research Journal, 18(1), 22-32.

Rodriguez-Dorans, E. (2018). Reflexivity and ethical research practice while interviewing on sexual topics. International Journal of Social Research Methodology, 21(6), 747-760.

Romocea, O. (2014). Ethics and emotions: A migrant researcher doing research among Romanian migrants. Sociological Research Online, 19(4), 12.

Ross, L.E. (2017). An account from the inside: Examining the emotional impact of qualitative research through the lens of 'insider' research. Qualitative Psychology, 4(3), 326-337.

Sampson, H., Bloor, M. \& Fincham, B. (2008). A price worth paying? Considering the 'cost' of reflexive research methods and the influence of feminist ways of 'doing'. Sociology. The Journal of the British Sociological Association, 42(5), 919-933.

Sandberg, S. \& Copes, H. (2013). Speaking with ethnographers: The challenges of researching drug dealers and offenders. Journal of Drug Issues, 43(2), 176-197. 
Scerri, C.S., Abela, A. \& Vetere, A. (2012). Ethical dilemmas of a clinician/researcher interviewing women who have grown up in a family where there was domestic violence. International Journal of Qualitative Methods, 11(2), 102-129.

Sinha, S. (2017). Ethical and safety issues in doing sex work research: Reflections from a field-based ethnographic study in Kolkata, India. Qualitative Health Research, 27(6), 893-908.

Sornes, J.O., Hybertsen, I.D. \& Browning, L. (2015). Identity challenges in field research: Three stories. Journal of Applied Communication Research, 43(1), 136-140.

Sriram, C.L., King, J.C., Mertus, J.A., Martin-Ortega, O. \& Herman, J. (2009). Surviving field research. Working in violent and difficult situations. New York: Routledge.

Stahlke, S. (2018). Expanding on notions of ethical risks to qualitative researchers. International Journal of Qualitative Methods, 17(1), 9.

Velardo, S. \& Elliot, S. (2018). Prioritising doctoral students' wellbeing in qualitative research. The Qualitative Report, 23(2), 311-318.

Wesser, G. (2018). Socialist biography and post-socialist ethnography: On the ethical dilemmas of trust and intimacy during fieldwork. Social Anthropology, 26(1), 60-73.

Wilinska, M. (2014). Shame on me ... emotions in the fieldwork on old age in Japan. Qualitative Social Work, 13(5), 602-618.

Woodby, L.L., Williams, B.R., Wittich, A.R. \& Burgio, K.L. (2011). Expanding the notion of researcher distress: The cumulative effects of coding. Qualitative Health Research, 21(6), 830-838.

Worley, R.M., Worley, V.B. \& Wood, B.A. (2016). 'There were ethical dilemmas all day long!': Harrowing tales of ethnographic researchers in criminology and criminal justice. Criminal Justice Studies, 29(4), 289-308.

Wray, N., Markovic, M. \& Manderson, L. (2007). 'Researcher saturation': The impact of data triangulation and intensive-research practices on the researcher and qualitative research process. Qualitative Health Research, 17(10), 1392-1402. 